\title{
The Macrogenoeconomics of Comparative Development
}

\author{
QuAMrul H. Ashraf and Oded GALOR*
}

\begin{abstract}
The importance of evolutionary forces for comparative economic performance across societies has been the focus of a vibrant literature, highlighting the roles played by the Neolithic Revolution and the prehistoric "out of Africa" migration of anatomically modern humans in generating worldwide variations in the composition of human traits. This essay provides an overview of the literature on the macrogenoeconomics of comparative development, underscoring the significance of evolutionary processes and of human population diversity in generating differential paths of economic development across societies. Furthermore, it examines the contribution of a recent hypothesis set forth by Nicholas Wade, regarding the evolutionary origins of comparative development, to this important line of research.
\end{abstract}

JEL classification codes: 011, N10, N30, Z10

Keywords: Comparative development, human evolution, natural selection, genes, race, the "out of Africa" hypothesis, genetic diversity, interpersonal diversity

\footnotetext{
*Ashraf: Department of Economics, Williams College, Schapiro Hall, 24 Hopkins Hall Drive, Williamstown, MA 01267 (email: Quamrul.H.Ashraf@williams.edu). Galor: Department of Economics, Brown University, 64 Waterman Street, Providence, RI 02912 (email: Oded Galor@brown.edu). We are grateful to Omer Moav, Ömer Özak, and especially the editor, Steven Durlauf, for helpful comments. Greg Casey and Matthew Jang provided superlative research assistance. Ashraf acknowledges research support from the NSF (SES-1338738), the Hellman Fellows Program, and the Oakley Center for Humanities and Social Sciences at Williams College. Galor acknowledges research support from the NSF (SES-1338426) and the Population Studies and Training Center (PSTC) at Brown University. The PSTC receives core support from the Eunice Kennedy Shriver National Institute of Child Health and Human Development (5R24HD041020). We are responsible for any errors.
} 


\section{Introduction}

The past two decades have witnessed the emergence of a large and influential body of research that has focused on uncovering the roots of comparative economic development across regions, countries, and ethnic groups. A significant portion of this line of inquiry has explored the influences of human evolution and the composition of human traits on comparative economic development across societies, highlighting the roles played by the Neolithic Revolution and the prehistoric "out of Africa" migration of anatomically modern humans in shaping variations in the composition of human traits among populations around the globe.

The exploration of the interaction between human evolution and the process of economic development has centered around two fundamental lines of injury. The first avenue examines the effect of the environment on the evolution of human traits as well as the contribution of this evolutionary process to economic development in the long run. The central hypothesis in this research avenue suggests that in the era following the Neolithic Revolution, Malthusian pressures acted as a key determinant of the size of a population and conceivably shaped, via the forces of natural selection, its composition as well. Lineages of individuals whose traits were complementary to the economic environment generated higher levels of income and, thus, a larger number of surviving offspring. Consequently, the gradual increase in the representation of these complementary traits in the population contributed to the process of development, the pace of the transition from stagnation to growth, and comparative economic development across societies. However, due to the egalitarian nature of hunter-gatherer societies, the forces of evolutionary selection within a society were largely muted prior to the Neolithic Revolution and the emergence of the nuclear family.

Subjecting hypothetical evolutionary processes to the scrutiny of evolutionary growth models, this body of research has identified several traits that may have been subjected to positive selection during the Malthusian era due to their conduciveness to human capital formation and economic development. In particular, these studies have highlighted the selection of innate preferences for quality rather than quantity of offspring, resistance to infectious diseases, human body size, predisposition towards entrepreneurial spirit, lactase persistence, conspicuous consumption, and time preference.

The second research avenue on the interaction between human evolution and the process of economic development has explored the persistent effect of the prehistoric exodus of Homo sapiens from Africa on the composition of traits and comparative economic development across societies from the dawn of civilization to the contemporary era. In particular, this line of research suggests that migratory distances from the cradle of mankind in East Africa to indigenous settlements across the globe diminished their levels of interpersonal diversity and, thereby, generated a persistent hump-shaped influence on development outcomes, reflecting a fundamental trade-off between beneficial and detrimental effects of diversity on productivity at the societal level. Although diversity may reduce interpersonal trust, cooperation, and social cohesiveness, and can thus adversely affect the productivity of society, complementarity across diverse productive traits may stimulate innovations and gains from specialization, and can thereby contribute to society's economic performance. Therefore, in the presence of diminishing marginal effects of diversity and homogeneity on productivity, the aggregate economic performance of 
ethnic groups, countries, or regions that are characterized by intermediate levels of diversity would be expected to be higher than that associated with excessively homogenous or heterogeneous societies.

Consistent with each of the fundamental building blocks of this hypothesis, interpersonal diversity, as proxied by diversity in genetic markers, appears to have contributed to ethnic and cultural heterogeneity, diminished interpersonal trust, and the emergence of civil conflicts. Moreover, evidence suggests that interpersonal diversity may foster innovative activity, occupational heterogeneity, and gains from specialization. Further, interpersonal diversity may have shaped the nature of both precolonial and contemporary political institutions. In particular, although diversity may have triggered the development of institutions for mitigating the adverse influence of population diversity on social cohesion, the contribution of diversity to economic inequality and class stratification may have ultimately led to the formation and persistence of extractive and autocratic institutions.

Recently, in A Troublesome Inheritance: Genes, Race and Human History, Nicholas Wade advances an intriguing hypothesis regarding the evolutionary origins of comparative economic development. Citing a wide range of evidence from evolutionary biology on the nature and pace of recent genetic adaptions in human populations, as well as evidence from evolutionary psychology and behavioral genetics on the association between somatic traits and social behaviors at the individual level, Wade argues that variation in selective pressures across regions of the globe has given rise to enduring differences in social behaviors across groups, thereby differentially shaping the nature of their institutions and, thus, their level of economic development. In particular, his hypothesis of comparative development suggests that in regions of the world that were historically characterized by higher population density and early statehood, favorable genetic traits (e.g., nonviolence, cooperation, and trust) that were initially concentrated among the rich elites gained an evolutionary advantage, proliferated over time, and contributed to the emergence of growth-enhancing institutions and a superior development trajectory.

This essay surveys the existing literature on the role of human evolutionary processes in comparative economic development and examines the contribution of Wade's hypothesis to this prominent body of research. Section 2 summarizes pertinent concepts and evidence from the field of human population genetics, highlighting differential evolutionary process across the globe. Section 3 provides an overview of the literature on the macrogenoeconomics of comparative development, underscoring the roles played by evolutionary processes and human diversity in generating differential development trajectories across societies. ${ }^{1}$ Section 4 summarizes Wade's thesis and provides a conceptual critique of his hypothesized

\footnotetext{
${ }^{1}$ The current review focuses on research that has been exploring the interaction of human evolution and the process of development at the societal level as well as the influence of the macrogenetic structure of human populations on comparative economic development across societies. It may be noted, however, that there exists a distinct but tangentially related literature that has been employing "genome-wide association studies" to explore the potential links between molecular genetics and either individual social behaviors in experimental settings or individual economic outcomes in observational data, including dispositions of fairness in ultimatum games (Wallace et al. 2007), cooperative behavior in trust games (Cesarini et al. 2008), risk preferences and giving behavior in dictator games (Cesarini et al. 2009), risk-taking in observed financial decisions (Cesarini et al. 2010), and observed levels of educational attainment (Rietveld et al. 2013; Okbay et al. 2016) and fertility behavior (Barban et al. 2016). The reader is referred to Beauchamp et al. (2011), Sacerdote (2011), Benjamin et al. (2012), and Conley and Fletcher (2017) for relevant surveys of this line of inquiry.
} 
evolutionary roots of comparative economic development. Section 5 conducts a discriminatory empirical examination of a fundamental prediction of the Wade's hypothesis versus alternative evolutionary theories of comparative development. Section 6 concludes.

\section{Pertinent Concepts and Evidence from the Field of Human Population Genetics}

\subsection{Differential Evolutionary Processes in Human Societies since the Neolithic Revolution}

Existing evidence suggests that the composition of genetic traits within a population has evolved rather swiftly in the course of human history and that differential evolutionary processes have transpired in human populations since the onset of the Neolithic Revolution. ${ }^{2}$ The transition from hunting and gathering to sedentary agriculture apparently triggered selection at genetic loci associated with skin pigmentation, resistance to infectious diseases, height, and diet. The differential onset of the Neolithic transition across regions has therefore contributed to the emergence of variations across populations in their composition of genetic traits.

Lactase persistence emerged among European and Near Eastern populations due to their early domestication of dairy-producing animals during the Neolithic Revolution, whereas in regions that experienced a delayed exposure to these domesticates, a larger fraction of the contemporary adult population continues to experience lactose intolerance (Bersaglieri et al. 2004; Burger et al. 2007; Tishkoff et al. 2007). Similarly, genetic immunity to malaria provided by the sickle cell trait is highly prevalent among the descendants of African populations whose early engagement in agriculture provided fertile breeding grounds for mosquitoes and, thus, elevated the incidence of malaria, whereas this trait is largely absent among descendants of populations that did not practice early agriculture (Livingstone 1958; Wiesenfeld 1967; Tishkoff et al. 2001).

Moreover, evidence based on comparing the genomes of ancient West Eurasians, dated to have lived between $6500 \mathrm{BCE}$ and $300 \mathrm{BCE}$, with the genomes of present-day Europeans indicates that adaptive immunity was apparently favored by natural selection due to the rise in population density and the associated increase in the prevalence of infectious diseases over the course of the Neolithic Revolution. In addition, lactase persistence, reduced blood plasma triglyceride levels, and regulators of vitamin D levels were selected to provide protection against the ergothioneine deficiency associated with the shift from hunter-gatherer to agricultural diets. Furthermore, lighter skin pigmentation (and to a lesser extent, lighter eye color) was subject to strong positive selection in some regions of the world, and early Neolithic migrants to southern Europe were under selection pressures that favored decreased height, while

\footnotetext{
${ }^{2}$ Voight et al. (2006) detected about 700 regions of the human genome in which genetic loci appear to have been reshaped by natural selection within the past 5,000 to 15,000 years. Moreover, Mekel-Bobrov et al. (2005) reports that a variant of the ASPM gene (a specific regulator of brain size in the lineage leading to Homo sapiens) arose in humans merely about 5,800 years ago and has since swept into high frequency under strong positive selection. Additional evidence on recent human adaptive evolution is provided by Sabeti et al. (2006), Hawks et al. (2007), and Nielsen et al. (2007).
} 
selection of increased height operated on the steppe populations that ultimately migrated to northern Europe (Mathieson et al. 2015). ${ }^{3}$

\subsection{The "Out of Africa" Origins of Worldwide Variations in Human Population Diversity}

The composition of individual traits within a population has also evolved in the course of the exodus of anatomically modern human from Africa. According to the widely accepted "out of Africa" hypothesis of human origins, the human species, having evolved to its anatomically modern form in East Africa nearly 200,000 years ago, embarked on populating the entire globe in a stepwise migration process commencing $90,000-60,000$ BP. The world map in Figure 1 depicts the approximate migration routes that characterized this prehistoric demic diffusion process.

\section{[INSERT FIGURE 1 HERE]}

The "out of Africa" migration was inherently associated with a reduction in the extent of genetic diversity in populations that settled at greater migratory distances from Africa. In particular, as follows from a serial founder effect, since the spatial diffusion of humans to the rest of the world occurred in a series of discrete steps, where in each step a subgroup of individuals left their parental colony to establish a new settlement farther away, carrying with them only a subset of the traits of their parental colony, the extent of genetic diversity observed within a geographically indigenous contemporary ethnic group decreases with distance along ancient migratory paths from East Africa (e.g., Harpending and Rogers 2000; Ramachandran et al. 2005; Prugnolle, Manica, and Balloux 2005; Ashraf and Galor 2013a).

Reflecting this chain of ancient population bottlenecks originating in East Africa, the scatter plot in Figure 2 depicts the negative influence of migratory distance from the cradle of mankind on intrapopulation genetic diversity in a sample comprising 53 globally representative ethnic groups from the HGDP-CEPH Human Genome Diversity Cell Line Panel (Cann et al. 2002). According to population geneticists, these groups have not only been indigenous to their current geographical locations but have also been largely isolated from genetic flows from other ethnic groups.

\section{[INSERT FIGURE 2 HERE]}

In order to measure the extent of diversity in genetic material across individuals in a given population (e.g., an ethnic group), population geneticists employ an index known as expected heterozygosity, which captures the probability that two individuals, selected at random from the relevant population, are genetically different from one another with respect to a given spectrum of genetic traits. In particular, a gene-specific expected heterozygosity index (i.e., the probability that two randomly selected individuals differ with respect to the genetic trait in question) is first constructed, based on the proportional representations of different alleles of this trait in the population, and upon measuring heterozygosity for a large number of genes or DNA loci, this information is averaged across loci to yield the overall expected heterozygosity for the relevant population.

\footnotetext{
${ }^{3}$ Independently of the Neolithic Revolution, natural selection led to the emergence of hemoglobin-regulating highaltitude adaptations among Tibetans, allowing carriers to survive in low-oxygen conditions (Simonson et al. 2010).
} 
The measure of expected heterozygosity for geographically indigenous ethnic groups is constructed by population geneticists using data on allelic frequencies for a particular class of DNA loci known as microsatellites. These DNA loci reside in non-protein-coding regions of the human genome (i.e., regions that do not directly result in phenotypic expression) and are therefore viewed as selectively neutral. For the purposes of examining the influence of interpersonal diversity on socioeconomic outcomes across populations, this measure possesses a key advantage of not being tainted by any unobserved heterogeneity in the forces of natural selection that may have operated on these populations since their exodus from Africa; forces that could have obscured the relationship predicted by the ancient serial founder effect. In addition, differential selection and its underlying forces could have also influenced socioeconomic outcomes, thus making it difficult to identify the causal socioeconomic influence of interpersonal diversity.

Nevertheless, to be conceptually meaningful for socioeconomic outcomes, the measure of neutral genetic diversity ought to serve as a valid proxy for diversity in phenotypically and behaviorally expressed traits. Reassuringly, as argued by Ashraf and Galor (2013a), the observed socioeconomic influence of expected heterozygosity in microsatellites reflects the positive relationship between diversity in microsatellites and intrapopulation heterogeneity in observable individual traits. This latent relationship can be inferred from mounting evidence in the fields of physical and cognitive anthropology on the existence of an ancient serial founder effect originating in East Africa on the observed worldwide patterns in various forms of intragroup morphological and cognitive diversity (Henn, Cavalli-Sforza, and Feldman 2012), including interpersonal diversity in skeletal features pertaining to cranial characteristics (Manica et al. 2007; von Cramon-Taubadel and Lycett 2008; Betti et al. 2009), dental attributes (Hanihara 2008), and pelvic traits (Betti et al. 2013), as well as intralingual phonemic diversity (Atkinson 2011). ${ }^{4}$ Importantly, in light of geneculture coevolution and transgenerational epigenetic inheritance, the socioeconomic influence of genetic diversity may be interpreted as reflecting the impact of interpersonal diversity in traits rooted in both "nature" and "nurture" as well as the interaction between the two. ${ }^{5}$

In addition to giving rise to the worldwide variation in interpersonal diversity within human societies, the prehistoric "out of Africa" dispersal also imparted a deep and long-lasting influence on the extent of genetic differentiation between societies, as measured by population geneticists using an index called $F_{S T}$ genetic distance. For any two populations, this index captures the extent of their combined genetic diversity that is unexplained by the population-weighted average of their respective expected heterozygosities. Following the splitting up of populations from one another during the "out of Africa" migration process, this residual genetic variation between populations arose from (i) random mutations that caused genetic drift within each population over time; and (ii) heterogeneity in environmentally driven selective pressures across their different eventual habitations. In particular, since migratory

\footnotetext{
${ }^{4}$ Moreover, a serial founder effect associated with the initial expansion of humans across Polynesian islands has been shown to exist in the context of intrapopulation diversity in functional markers pertaining to material culture (Rogers, Feldman, and Ehrlich 2009).

${ }^{5}$ For instance, introducing the concept of "genetic nurture," Kong et al. (2018) find that parental genotype associated with the educational attainment of parents in turn affects the educational attainment of children even when the latter do not carry the relevant allelic variants, thus suggesting the intergenerational propagation of traits that may initially be rooted in "nature" through the transmission mechanism of "nurture."
} 
distance between a pair of populations partly reflects the length of time elapsed since they diverged from their common ancestral population, and because it also reduces the likelihood that they would have subsequently come into contact with one another, a direct implication of the "out of Africa" hypothesis is that pairwise $F_{S T}$ genetic distance increases with the pairwise migratory distance between populations. Using a measure of $F_{S T}$ genetic distance based on selectively neutral genetic markers (i.e., distance that only captures genetic drift due to random mutations), the scatter plot in Figure 3 depicts the aforementioned relationship arising from "isolation by distance" across all pairs of 53 ethnic groups from the HGDP-CEPH Human Genome Diversity Cell Line Panel.

\section{[INSERT FIGURE 3 HERE]}

\section{Evolution, Diversity, and Comparative Development}

\subsection{Human Evolution and Long-Run Economic Growth}

The impact of the economic environment on the evolution of human traits and the contribution of this evolutionary process to long-run economic development has been the subject of an intensive research program over the past two decades. The fundamental hypothesis in this body of research, originating in Galor and Moav (2002), suggests that in the era following the Neolithic Revolution, Malthusian pressures not only acted as a key determinant of the size of a population but conceivably shaped, via the forces of natural selection, its composition as well. Lineages of individuals whose traits were complementary to the economic environment may have generated higher levels of income and, thus, a larger number of surviving offspring. Consequently, the gradual increase in the representation of these traits in the population over time may have contributed to the process of development, the pace of the transition from stagnation to growth, and comparative economic development across societies.

In line with the evidence discussed in Section 2.1, regarding human evolutionary adaptations since the onset of the Neolithic Revolution, this research additionally suggests that due to the egalitarian nature of hunter-gatherer societies, the forces of evolutionary selection within a society were largely muted prior to the adoption of farming and the emergence of the nuclear family. The transition to sedentary agriculture and the emergence of property rights, however, may have subsequently reinforced the association between parental income and reproductive success and, thus, amplified the pace of these evolutionary processes (Galor and Moav 2002).

Subjecting hypothetical evolutionary processes to the scrutiny of evolutionary growth models, this body of research has identified several traits that may have been subjected to positive selection during the Malthusian era due to their conduciveness to human capital formation and economic development. In particular, these studies have highlighted the selection of innate preferences for quality rather than quantity of offspring (Galor and Moav 2002), resistance to infectious diseases (Galor and Moav 2007), human body size (Lagerlöf 2007), predisposition towards entrepreneurial spirit (Galor and Michalopoulos 
2012), lactase persistence (Cook 2014), conspicuous consumption (Collins, Baer, and Weber 2015), and time preference (Galor and Özak 2016). ${ }^{6}$

In particular, Galor and Moav (2002) have advanced the hypothesis that during the Malthusian epoch, natural selection may have brought about a gradual increase in the prevalence of traits associated with predispositions towards the quality rather than quantity of offspring. The positive influence of this evolutionary process on investment in human capital may have stimulated technological progress and contributed to the reinforcing interaction between human-capital investment and technological progress that ultimately triggered the demographic transition and brought about a state of sustained economic growth. The quantitative analysis of Collins, Baer, and Weber (2014) corroborates this hypothesis.

An empirical test of the hypothesis advanced by Galor and Moav (2002) has recently been conducted by Galor and Klemp (2014). Using an extensive data set of genealogical records for nearly half a million individuals in Quebec between the 16th and 18th centuries, their study suggests that moderate fecundity, and thus predisposition towards investment in child quality, was conducive for long-run reproductive success, reflecting the negative influence of higher fecundity on the survivability, marital age, and education of each offspring. Interestingly, the conditions that were faced by the founder population of Quebec during this time period of high fertility may have resembled the environment that anatomically modern humans confronted during their migration from Africa, as they settled new territories where the carrying capacity of the environment was an order of magnitude greater than the size of the founder population. Thus, the findings suggest that during the high-fertility regime of the Malthusian epoch, in which evolutionary forces could have had a significant impact on the composition of the population (e.g., during the Neolithic transition and the formation of sedentary agricultural communities), natural selection favored individuals with a larger predisposition towards child quality, contributing to human capital formation, the onset of the demographic transition, and the evolution of societies from an epoch of stagnation to sustained economic growth. ${ }^{7}$

The evolutionary origins of worldwide variations in the resistance to infectious diseases, as well as their implications for comparative development, have been examined by Galor and Moav (2007). This research hypothesizes and provides empirical evidence that the socioeconomic transformations associated with the Neolithic Revolution triggered an evolutionary process that imparted positive selective pressures on the resistance to infectious diseases. Consequently, heterogeneity across societies in their length of exposure to this evolutionary process, as captured by their differential timing of the transition to sedentary agriculture, may have significantly shaped the contemporary global distribution of human

\footnotetext{
${ }^{6}$ It may be noted that the interaction between human evolution and the process of development, as emphasized by this literature, may capture both cultural and genetic propagation mechanisms for the intergenerational transmission of individual traits (Weibull and Salomonsson 2006; Bisin and Verdier 2011; Bowles and Gintis 2011; Robson and Samuelson 2011; Doepke and Zilibotti 2014).

${ }^{7}$ While Galor and Klemp (2014) uncover evidence in line with Galor and Moav's (2002) theoretical predictions for the pre-demographic-transition Malthusian epoch, the findings of Kong et al. (2017) are consistent with their predictions for the post-demographic-transition era. Specifically, based on data for Icelandic individuals born between 1910 and 1990, Kong et al. (2017) uncover evidence that the lower fertility linked with higher investment in child quality has led to the negative selection of genomic variants associated with educational attainment.
} 
longevity. In a related paper, Cook (2015) further links this evolutionary process to the degree of intrapopulation genetic diversity in the human leukocyte antigen (HLA) system.

Galor and Michalopoulos (2012) have explored the coevolution of entrepreneurial spirit and the process of long-run economic development. Their analysis suggests that Darwinian selection of entrepreneurial traits may have played a significant role in the process of economic development and influenced the dynamics of inequality both within and across societies. Specifically, they argue that entrepreneurial spirit evolved nonmonotonically over the course of human history. In early stages of development, risk-tolerant growth-promoting traits may have possessed an evolutionary advantage, and their increased representation in the population over time accelerated the pace of technological progress and, thereby, the process of economic development. In mature stages of development, however, risk-averse traits may have gained an evolutionary advantage, diminishing the growth potential of advanced economies and contributing to convergence in economic growth across countries.

The coevolution of subsistence consumption, the ability to engage in efficient and diversified food procurement strategies, and the process of development has also been examined by this line of research. Specifically, Lagerlöf (2007) has argued that resource depletion associated with technological progress and rising population density during the Malthusian epoch may have triggered a shift in reproductive advantage from large to small body sizes, thereby generating an endogenous reversal of the long-run time trend in human body mass. In addition, Cook (2014) has provided empirical evidence documenting that heterogeneity across regions in the contemporary prevalence of the lactase persistence trait is positively associated with differences in the level of precolonial economic development, presumably reflecting the reproductive success and the productivity-enhancing benefits associated with this post-Neolithic adaptation that confers the ability of digest milk into adulthood. ${ }^{8}$ Further, Collins, Baer, and Weber (2015) have argued that female mating preferences may have increased the reproductive success of males predisposed to engage in conspicuous consumption in order to credibly signal their quality, and because conspicuous consumption is funded through increased participation in the labor force, the increase in the prevalence of signaling males in the population may have given rise to an increase in economic activity that contributed to long-run economic growth.

Finally, Galor and Özak (2016) have explored the evolutionary origins of the contemporary distribution of time preference across regions. They advance the hypothesis and provide empirical evidence that geographical variation in the natural return to agricultural investment may have had a persistent effect on the distribution of time preference across societies. In particular, exploiting a natural experiment associated with the expansion of suitable crops for cultivation in the course of the Columbian Exchange, these authors find that preindustrial agro-climatic characteristics that were conducive to higher returns from agricultural investment may have triggered selection and learning processes that have had a persistent positive effect on the prevalence of long-term orientation.

\footnotetext{
${ }^{8}$ The long-run codetermination of human physiology and economic development is explored further by Dalgaard and Strulik $(2015,2016)$.
} 
In contrast to the literature on the interaction between human evolution and the process of development that emphasizes the "direct effects" of the composition of human traits in society on economic outcomes, a complementary line of research, originating in Spolaore and Wacziarg (2009), has exploited human evolutionary data to empirically examine the "barrier effects" of the extent of cultural and biological divergence between societies on their relative ability to adopt technological and institutional innovations from the global frontier and, thus, on the diffusion of economic development. Notably, in these contributions (surveyed in Spolaore and Wacziarg 2014), the extent of divergence between societies is proxied by their pairwise or dyadic $F_{S T}$ genetic distance in genetic markers that are mostly selectively neutral. Hence, this measure predominantly captures the time elapsed since two societies diverged from a common ancestral population and, therefore, the time over which intersocietal cultural and biological differences could have accumulated due to the forces of cultural and genetic drift, differential selection, and divergent gene-culture coevolution. In line with the "barrier effects" arising from cultural and biological divergence, this area of inquiry has established the reduced-form contribution of pairwise $F_{S T}$ genetic distance between societies to dyadic differences in income per capita, technology adoption, and institutional quality, amongst other outcomes. ${ }^{9}$

\subsection{Interpersonal Diversity and Comparative Development across Societies}

The importance of interpersonal diversity within populations has been the focus of a recent but vibrant research program in the academic literature on the deep roots of comparative development, originating in Ashraf and Galor (2013a). This research has advanced the hypothesis that greater migratory distances from the cradle of mankind in East Africa to indigenous settlements across the globe reduced their levels of interpersonal diversity and, thereby, generated a persistent hump-shaped influence on development outcomes, reflecting the trade-off between beneficial and detrimental effects of diversity on productivity at the societal level. Diversity may have enhanced economic development by widening the spectrum of individual skills, abilities, and cognitive approaches, which may have fostered innovative activity, stimulated specialization, and facilitated more rapid adaptation to changing technological environments. Conversely, by widening the spectrum of individual values, beliefs, preferences, and predispositions in social interactions, diversity may have reduced trust and social cohesion, generated inefficiencies in the provision of public goods, hampered economic coordination, and, therefore, adversely affected economic performance.

If the social benefits and costs of diversity are diminishing at the margin, diversity would be expected to confer a hump-shaped effect on economic development. Thus, the aggregate economic performance of ethnic groups, countries, or regions that are characterized by intermediate levels of diversity is expected to be higher than that associated with excessively homogenous or heterogeneous societies.

Exploiting the data on genetic diversity discussed in Section 2.2 as a proxy measure of interpersonal diversity, Ashraf and Galor (2013a) empirically examine their prediction regarding the trade-off between

\footnotetext{
${ }^{9}$ The study by Becker, Enke, and Falk (2018) is another example of the application of pairwise $F_{S T}$ genetic distance as a measure of the temporal divergence between societies. Specifically, the authors uncover evidence linking this measure with dyadic intersocietal differences in economic preferences, particularly risk aversion and the prosocial traits of altruism, positive reciprocity, and trust.
} 
the beneficial and detrimental effects of the degree of diversity on productivity at the societal level. Consistent with their hypothesis, they find that interpersonal diversity, as determined predominantly by the serial founder effect associated with the prehistoric "out of Africa" migration process, does indeed confer a significant hump-shaped influence on income per capita, explaining 16 percent of the worldwide cross-country variation in the standard of living in the year 2000.

Although Ashraf and Galor's main focus is on contemporary comparative development, they confirm the hump-shaped influence of diversity on economic development in both historical and contemporary time periods, demonstrating that diversity within societies has shaped their comparative development since well before the advent of the Industrial Revolution. In the preindustrial era, comparative development was characterized by Malthusian forces - namely, gains in productivity at the societal level were channeled primarily towards population growth rather than growth in income per capita. During this era, more developed societies were therefore characterized by higher population density, rather than a higher standard of living (Ashraf and Galor 2011). Thus, Ashraf and Galor's historical analysis of the influence of interpersonal diversity on comparative development focuses on explaining the variation across preindustrial societies in population density in the year 1500 .

To overcome sample limitations and potential concerns about reverse causality associated with the use of observed genetic diversity, the authors exploit the strong explanatory power of migratory distance from East Africa for the worldwide variation in observed genetic diversity across ethnic groups in the HGDPCEPH sample in order to generate a measure of predicted interpersonal diversity for all societies around the world, based on their respective geographical locations in the year 1500. Importantly, prior to the discovery of the New World and the great intercontinental migrations of the colonial era, the geographical locations of historical societies largely reflected the locations to which their ancestral populations had arrived at the end of their prehistoric "out of Africa" migration from the cradle of mankind, and as such, the diversity of a precolonial society was presumably determined overwhelmingly by the ancient serial founder effect originating in East Africa.

As depicted by the scatter plot in Panel A of Figure 4, employing the measure of predicted diversity, the authors document a hump-shaped influence of diversity on productivity in the year 1500, as captured by population density, in a sample of observations spanning the entire globe. Notably, the depicted relationship accounts for the potentially confounding effects due to heterogeneity across societies in the timing of the Neolithic Revolution and in various geographical factors relevant for their historical development, as well as the confounding effects arising from unobserved cross-continental differences. This finding is robust to a large number of sensitivity checks, including "placebo tests" showing that a similar hump-shaped pattern does not exist when employing either aerial distance from East Africa or migratory distances from other geographical locations. In addition, as depicted by the scatter plot in Panel B of Figure 4, the finding also holds when urbanization rate in the year 1500 is employed as an alternative measure of comparative development across preindustrial societies.

[INSERT FIGURE 4 HERE] 
Ashraf and Galor's analysis of contemporary comparative development exploits data on the ethnic compositions of modern national populations, which reflect the great intercontinental and interregional migrations over the past half millennium. Specifically, it incorporates this information to construct a country-level measure of contemporary population diversity that takes into account not only the expected heterozygosity of each ethnic group in a national population but also the pairwise genetic distances amongst these constituent ethnic groups. ${ }^{10}$ Applying their measure of contemporary population diversity, the authors find a significant hump-shaped influence of diversity on income per capita in the year 2000. This relationship, depicted by the scatter plot in Panel A of Figure 5, accounts for the potentially confounding effects arising from cross-country heterogeneity in the timing of the Neolithic Revolution, various geographical, cultural, and institutional correlates of contemporary economic development, and unobserved continent-specific characteristics. The relationship is additionally robust to controlling for population density in the year 1500, indicating that the hump-shaped influence of diversity does not merely reflect long-run persistence in economic development. Moreover, it continues to hold when limiting the sample to countries in which the overwhelming majority of the population has remained geographically native since the precolonial era, thus alleviating concerns regarding the endogeneity of international population flows over the past five hundred years. Further, the level of diversity most conducive to economic development is found to be higher in the contemporary period relative to the preindustrial era, consistently with the underlying premise that the benefits of diversity should be more pronounced in an increasingly demanding technological environment, while the costs of diversity can be mitigated by modern education systems that promote social cohesiveness.

\section{[INSERT FIGURE 5 HERE]}

Confronting the possibility that income per capita in the modern world could be noisily measured, especially for less-developed economies, Ashraf, Galor, and Klemp (2014) find that the hump-shaped influence of diversity on contemporary comparative development additionally holds when relative prosperity is measured by the cross-country variation in per-capita adjusted nighttime luminosity, as observed by satellites from outer space. These findings lend further credence to the hypothesis that diversity may account for a significant portion of the worldwide variation in contemporary living standards.

Moreover, Ashraf, Galor, and Klemp (2015) have empirically examined the influence of diversity on productivity at the ethnic group level, while accounting for the potentially confounding effects arising from observed heterogeneity in various ethnicity-specific geographical, cultural, and institutional factors, as well as unobserved heterogeneity in country-specific characteristics. This research finds that observed diversity in a worldwide sample of 230 ethnic groups (Pemberton, DeGiorgio, and Rosenberg 2013), as well as predicted diversity (based on migratory distance from East Africa) in a global sample of 1,331 ethnic groups, confers a significant hump-shaped influence on economic prosperity, suggesting that the variation in interpersonal diversity across ethnic homelands has contributed to variations in economic development across ethnic groups and regions at the subnational level. The hump-shaped influence of

\footnotetext{
${ }^{10}$ Additional details regarding the construction of this measure of contemporary population diversity are provided in the online appendix of Ashraf and Galor (2013a).
} 
observed diversity on productivity at the ethnic group level, as reflected by the per-capita adjusted nighttime luminosity of an ethnic homeland, is depicted by the scatter plot presented in Panel B of Figure 5 .

This analysis at the ethnic group level provides the first-best setting for confirming the robustness of the main prediction of Ashraf and Galor's hypothesis to using Pemberton, DeGiorgio, and Rosenberg's (2013) data on observed diversity in the extended sample of ethnic groups. Nevertheless, the results for the influence of interpersonal diversity on comparative development in both precolonial and modern periods are robust in a second-best country-level setting. In particular, following Ashraf and Galor's (2013a) methodology, one can generate measures of predicted diversity for a globally representative sample of countries, based on their respective migratory distances from East Africa. Since the coefficients of the estimated relationship between migratory distance and observed diversity are virtually identical in the HGDP-CEPH sample versus the extended sample of ethnic groups, the hump-shaped influence of predicted diversity on both historical and contemporary cross-country comparative development remains unaffected. ${ }^{11}$

Finally, it has also been shown that migratory distance from the cradle of mankind may have imparted a reduced-form hump-shaped influence on comparative economic development (Ashraf and Galor 2013a). Although the reduced-form influence of migratory distance from East Africa appears to operate through its impact on interpersonal diversity as observed in the HGDP-CEPH sample, it is plausible that migratory distance per se has had direct effects on economic development, independently of its influence through interpersonal diversity, potentially reflecting the self-selection of individuals into migration and differential evolutionary processes that may have taken place in the course of the demic expansion of anatomically modern humans from Africa.

\footnotetext{
${ }^{11} \mathrm{~A}$ third-best approach would be to conduct a preliminary (noninferential) exploration of the association between observed diversity and economic prosperity at the country level. This is the approach taken by Rosenberg and Kang (2015), who argue that the hump-shaped pattern between observed diversity and historical population density is statistically insignificant in a 39-country sample, constructed by averaging expected heterozygosity across the subset of ethnic groups that are observed within each country. However, their attempt to use this approach to test for the hump-shaped influence of interpersonal diversity on economic prosperity is fundamentally flawed for two major reasons. First, because the subset of only observed ethnic groups in a country is not necessarily representative of the country's entire population, and since the ethnic groups from their extended sample span only 39 (globally nonrepresentative) countries, their study is severely marred by sample selection bias at the country level. Specifically, the actual presence of a hump-shaped cross-country association between observed diversity and economic prosperity cannot be confirmed or rejected based on a nonrepresentative sample of country populations. Second, observed diversity may reflect past socioeconomic outcomes such as intraregional social conflicts and migrations that are themselves driven by past economic prosperity. Thus, Rosenberg and Kang's explorative analysis is afflicted by issues of reverse causality and omitted variables that serve to mask the existence of a hump-shaped relationship between diversity and economic prosperity. Indeed, even in the context of their nonrepresentative sample of country populations, Ashraf, Galor, and Klemp (2018) have found that a highly significant hump-shaped association emerges between observed diversity and historical population density once a sufficient set of potential geographical confounders is accounted for. Moreover, as discussed in the main text and depicted in Panel B of Figure 5, conditional on employing a valid statistical methodology, the main prediction of Ashraf and Galor's hypothesis is fully robust to exploiting genetic data from the extended sample of ethnic groups.
} 
Mechanisms: The reduced-form hump-shaped impact of diversity on productivity suggests several potential mechanisms through which diversity can influence economic performance, reflecting various elements of the trade-off between the social costs and benefits of diversity. Ashraf and Galor (2013a) furnish cross-country empirical evidence for two such mechanisms. Specifically, their analysis suggests that contemporary population diversity imparts (i) a positive influence on innovative activity (as reflected by the average annual number of scientific articles per capita in the 1981-2000 time period); and (ii) a negative influence on the degree of social cohesion (as reflected by the prevalence of interpersonal trust in survey data on individual values, collected over the 1981-2008 time period). These relationships between diversity, on the one hand, and either innovative activity or the prevalence of trust, on the other, are depicted by the scatter plots in Panels A and B of Figure 6.

\section{[INSERT FIGURE 6 HERE]}

Further evidence on some of the mechanisms through which diversity can affect economic prosperity is provided by several other papers in this research program. Bearing in mind that ethnic diversity has been shown to be associated with various dimensions of economic underperformance at the national level (e.g., Easterly and Levine 1997; Alesina et al. 2003; Alesina and La Ferrara 2005), the evidence uncovered by Ashraf and Galor (2013b) suggests that prehistorically determined interpersonal diversity could be an underlying cause of different manifestations of the ethnolinguistic fragmentation of national populations. Specifically, their hypothesis suggests that following the "out of Africa" migration, the initial endowment of population diversity in a given location may have catalyzed the formation of distinct groups at that location through a process of endogenous group selection, reflecting the trade-off associated with the scale and internal cohesion of each group. Although a larger group can benefit from economies of scale, it is more likely to be less cohesive due to costly coordination. Thus, in light of the added contribution of interpersonal diversity to the lack of cohesiveness of a group, a larger initial endowment of population diversity in a given location may have given rise to a larger number of groups. Over time, due to the forces of "cultural drift" and "biased transmission" of cultural markers that serve to distinguish "insiders" from "outsiders" of a group (e.g., language dialects, customs and traditions, norms of social conduct), intergroup divergence in such markers became more pronounced, leading to the formation of distinct collective identities along ethnic lines.

In line with this hypothesis, interpersonal diversity at the national level is found to impart a strong positive influence on various alternative measures of ethnolinguistic diversity, while accounting for the potentially confounding influence of the timing of the Neolithic Revolution, the time elapsed since initial human settlement, colonial history, the geographical determinants of ethnic diversity, and unobserved continentspecific factors. Further, to address the issue of causality, the findings are shown to hold in a sample restricted to only countries from the Old World, which were largely immune from the potentially endogenous intercontinental migrations of the colonial era. In the same vein, the findings are also shown to be robust to employing prehistoric migratory distance from East Africa as a plausibly exogenous source of variation in contemporary diversity in a global sample of countries. The positive influence of interpersonal diversity on the number of ethnic groups at the national level, as uncovered by Ashraf and Galor (2013b), is depicted by the scatter plot in Panel C of Figure 6. 
Intrasocietal conflicts are another mechanism though which the interpersonal diversity of a population can lead to its economic underperformance. Exploiting variations across countries and ethnic groups, Arbatlı et al. (2018) find that population diversity has been a significant contributor to the risk and intensity of both historical and contemporary internal conflicts, conditional on various geographical, cultural, and institutional correlates of conflict, outcomes of economic development, and unobserved continental or regional characteristics. Importantly, because unlike standard measures of ethnic diversity, interpersonal diversity captures both intergroup and intragroup differences in individual traits, the latter possesses explanatory power for not only intergroup conflicts but intragroup conflicts as well. This research additionally shows that interpersonal diversity may have contributed to conflicts in society through the channels of greater ethnic fragmentation, reduced interpersonal trust, and sharper divergence in preferences for public goods and redistributive policies. The scatter plots in Panels $D$ and $E$ of Figure 6 respectively depict the positive influence of interpersonal diversity on the frequency of civil conflicts and on heterogeneity in political preferences at the national level.

The emergence and persistence of autocratic forms of societal governance is yet another mechanism through which interpersonal diversity may have given rise to contemporary economic underperformance. Specifically, Galor and Klemp (2017) advance the hypothesis that although prehistorically determined interpersonal diversity may have raised society's demand for formal institutions that mitigated the adverse influence of diversity on social cohesion, the contribution of diversity to economic inequality and class stratification within societies may have also shaped institutional development towards more extractive and autocratic forms of governance. Exploiting variations across precolonial ethnic homelands, the authors find that conditional on the potentially confounding effects of various geographical factors and unobserved continental characteristics, interpersonal diversity imparts a positive influence on the prevalence of precolonial autocratic institutions and that this relationship plausibly reflects the dual impact of diversity on the demand for formal institutions and the emergence of social stratification. Furthermore, the authors document that the spatial variation in interpersonal diversity across the globe may have contributed to the cross-country variation in contemporary degrees of autocracy, partly reflecting the persistence of institutional, cultural, and compositional characteristics of populations over time.

Beyond the aforementioned studies that highlight some of the mechanisms associated with the social costs of interpersonal diversity, Depetris-Chauvin and Özak (2017) present evidence in support of its social benefits. ${ }^{12}$ In particular, the authors empirically examine Ashraf and Galor's hypothesis that interpersonal

\footnotetext{
${ }^{12}$ The beneficial effects of interpersonal diversity on economic development are also documented empirically by Ager and Brückner (forthcoming). Exploiting variations across counties in the United States in the late nineteenthcentury, these authors find that county-level populations that experienced a larger initial increase in their genetic diversity due to the arrival of European immigrants also subsequently experienced higher rates of growth in both income and scientific patents per capita during the 1870-1920 time horizon. In another interesting study by Delis et al. (2017), the authors exploit panel variations across firms listed in the stock markets of North America and the United Kingdom to show that adding members to a firm's board of directors from countries of origin with differing levels of genetic diversity increases its corporate performance. The authors hypothesize that their finding reflects the productivity-enhancing benefits of interpersonal differences in cultural, psychological, physiological, and other traits that cannot be captured by alternative measured indices of diversity.
} 
diversity could have fostered the division of labor in society by widening the spectrum of individual skills, abilities, and cognitive approaches. Exploiting variations observed across precolonial ethnic homelands, they document that, consistently with Ashraf and Galor's initial hypothesis, prehistorically determined interpersonal diversity may have conferred a positive influence on the degree of economic specialization in different production activities in a society, thereby fostering its proclivity to engage in and reap the economic benefits of market-based exchange. ${ }^{13}$ The authors additionally show that present-day populations residing in regions that were characterized by a higher degree of precolonial economic specialization tend to exhibit significantly greater occupational heterogeneity and a higher level of economic development.

Interestingly, the beneficial impact of interpersonal diversity on productivity has also been documented at a much lower level of aggregation than countries or ethnic groups. Specifically, exploiting variations across high schools in the state of Wisconsin, Cook and Fletcher (2017) find that the heterozygosity of the student body of a high school in 1957 may have conferred a significant positive influence on the economic performance of the school's graduates later in life, as captured by completed years of schooling, measures of occupational prestige of the graduate's first job, and family income in 1974 and $1992 .{ }^{14}$ Importantly, because these findings are established by exploiting variations within a single state, they are unaffected by cross-country (and even within-country cross-state) confounders. In addition, because the high-school student bodies in the authors' data set were entirely comprised of individuals of European ancestry, the results are unlikely to be afflicted by issues of population stratification that could otherwise conflate the influence of heterozygosity with those of ethnicity or ancestral origins on economic outcomes.

Criticism: The literature on the influence of interpersonal diversity on comparative development across societies has attracted the attention of the scholarly community beyond the discipline of economics and, given methodological divisions, has perhaps unsurprisingly generated unfounded criticisms. In particular, three criticisms have been raised: (a) the precolonial population data employed for the analysis of historical development are imperfectly measured, and in particular, the population sizes of precolonial Amerindian societies are underestimated; (b) expected heterozygosity in neutral genetic markers, employed to capture the degree of interpersonal diversity within a population, does not reflect diversity in functional (phenotypic) markers and, therefore, cannot influence behavioral and social interactions; and (c) the findings can be used to justify disturbing policy prescriptions, designed to "engineer" an "optimal" diversity level in a population.

These criticisms, however, are unfounded for the following reasons:

\footnotetext{
${ }^{13}$ Interestingly, as one would expect from preindustrial production activities, in which characteristics of the physical environment and individual abilities behave as complementary inputs, the research also documents that the degree of agro-ecological and agro-climatic heterogeneity reinforces the positive influence of interpersonal diversity on the emergence of economic specialization in precolonial societies.

14 The authors additionally provide evidence in line with a novel behavioral mechanism - namely, that exposure to more genetically diverse schooling environments may have shaped individual personality traits towards greater creativity and openness to new ideas and, thus, behaviorally conditioned the individual for greater socioeconomic success later in life.
} 
a. Ashraf and Galor's historical analysis accounts for the possibility that the data on population density in the year 1500 could be afflicted by measurement errors, demonstrating that this issue has no bearing on the validity of their empirical findings. First, population density is the dependent variable in their historical analysis, and as such, classical measurement error in this variable does not introduce any bias to the estimates of the hump-shaped influence of diversity on historical development. In fact, in the absence of classical measurement error, the statistical significance of their estimates would be even higher. Second, if there are systematic differences across continents in the noisy measurement of historical population density (e.g., if historical population density in the Americas is indeed consistently underestimated), bias arising from these differences is accounted for by the continent fixed effects in their analysis. Specifically, the influence of diversity on historical development is identified by exploiting intersocietal variations within continents rather than across continents. Third, as depicted by the scatter plot in Panel B of Figure 4, employing an alternative measure of historical development - namely, the extent of urbanization in the year 1500 (obtained from sources that are entirely independent of the source for historical population density data) - does not qualitatively alter the hump-shaped influence of interpersonal diversity on historical development. Lastly, issues related to the noisy measurement of historical population density are irrelevant for Ashraf and Galor's main analysis of contemporary comparative development, in which the dependent variable is income per capita in the year 2000.

b. Indeed, expected heterozygosity in neutral genetic markers, employed for the measurement of the degree of interpersonal diversity within a population, does not directly reflect diversity in functional (phenotypic) markers. Nevertheless, as elaborated in Section 2.2, the observed socioeconomic influence of expected heterozygosity in microsatellites reflects the positive relationship between diversity in microsatellites and intrapopulation heterogeneity in morphologically and behaviorally expressed individual traits. In particular, as is the case with expected heterozygosity in neutral genetic markers, evidence suggests that migratory distance from East Africa imparts a negative influence on various forms of intragroup phenotypic diversity (Henn, Cavalli-Sforza, and Feldman 2012), including intralingual phonemic diversity, as well as interpersonal diversity in skeletal features pertaining to cranial characteristics, dental attributes, and pelvic traits.

c. The view that Ashraf and Galor's research can be used to justify disturbing policy prescriptions is distorted because (i) it disregards the proximate mechanisms though which interpersonal diversity affects economic outcomes, and (ii) it fails to recognize that one of the fundamental insights of this research program is the increasing importance of diversity for economic prosperity over the course of human history. As elaborated in the following section, there exists a far more nuanced view of the possible broader implications for economic policy from this research.

Policy Implications: Ashraf and Galor's analysis documents a fundamental trade-off associated with the influence of interpersonal diversity, as reflected by genetic diversity, on economic performance. The fact that diversity has been a deep determinant of economic development, however, does not imply that the composition of hereditary traits in a population governs its economic destiny. As explained in Section 2.2, the influence of diversity on productivity reflects both genetic and cultural components, implying that a society can shape the context in which the existing diversity of its population influences socioeconomic 
outcomes, by enacting policies to harness the beneficial effects of the existing level of diversity and mitigate its potentially detrimental consequences.

The controversy over the implications of Ashraf and Galor's findings has focused on their assertion that intermediate levels of interpersonal diversity in heritable traits tend to be most conducive to economic development, thereby leading uninformed critics to suggest that this work could be used to justify the forcible movement or "engineering" of populations. This viewpoint, however, disregards the key argument that the influence of diversity on development operates through various proximate mechanisms. Instead, the implications for policymaking from Ashraf and Galor's analysis are that policies should be aimed at conditioning the intervening channels. Specifically, overly diverse societies could focus on fostering interpersonal trust and mediating the potential for social conflict, by encouraging civic participation, improving the quality of political institutions, and mitigating inefficiencies and distortions in the provision of public goods. Overly homogenous societies, on the other hand, could aim to increase diversity in skills, occupations, and training programs in order to foster specialization and innovative activity. In both cases, the orientation of the educational system appears to be the most promising avenue: education can help instill the cultural values of tolerance needed in overly diverse societies, and it can also promote cultural receptiveness to different types of productivity-enhancing knowledge that may be lacking in overly homogenous societies.

\section{Wade's Hypothesis of Comparative Development}

\subsection{Overview}

Nicholas Wade's A Troublesome Inheritance: Genes, Race and Human History is composed of two substantive parts. The first part of the book provides an accessible, engaging, and mostly credible account of human evolutionary history, citing much of the scientific evidence discussed earlier in Section 2 on differential genetic adaptions across populations since the onset of the Neolithic Revolution (e.g., lactase persistence, resistance to infectious diseases, and high-altitude adaptations), as well as the evidence on the impact of the prehistoric "out of Africa" migration in generating worldwide patterns of human genetic variation. Furthermore, it discusses some intriguing evidence from evolutionary psychology and behavioral genetics on the association between somatic traits and social behaviors such as cooperation and aggression.

The second part of the book is more speculative, extrapolating from the different pieces of evidence revealed in the first part to weave together an evolutionary hypothesis about the roots of comparative economic development across world regions. Wade's hypothesis suggests that heterogeneity across regions in the selection of genetic traits, associated with the social behaviors of nonviolence, cooperation, and trust, has given rise to interregional variation in the nature of institutions and, thus, in the level of economic development. Specifically, he posits that the genetic predispositions of European and East Asian societies towards economic prosperity, as well as the genetically determined unsuitability of African societies to adopt market-friendly Western institutions, have governed the differential development trajectories across world regions. 
For instance, Wade asserts that: "[w]hen North Korea adopts market-friendly institutions, a safe prediction is that it would in time become as prosperous as South Korea. It would be far less safe to predict that Equatorial Guinea or Haiti needs only better institutions to attain a modern economy; their people may not have yet had the opportunity to develop ingrained behaviors of trust, nonviolence and thrift that a productive economy requires" (p. 188). ${ }^{15} \mathrm{He}$ further argues that: "[t]he fact that China, Japan and South Korea developed modern economies so easily, once the appropriate institutions were in place, is evidence that their populations, like those of Europe, had undergone equivalent behavioral changes to those documented in England" (p. 178). In addition, Wade also hypothesizes that genetic differences between East Asians and Europeans have favored Europeans in comparative development, highlighting genetic predispositions towards "openness to new ideas" among European societies versus predispositions towards excessive conformity in East Asian societies (pp. 166, 218). ${ }^{16}$

\subsection{Evolutionary Processes during the Malthusian Epoch}

Wade's general narrative on human evolution and economic development echoes the economic literature surveyed in Section 3.1 that has examined the interaction between human evolution and the process of economic development.

Wade's hypothesis of comparative economic development highlights regional variation in the intensity of selection of individual traits that are conducive to growth-enhancing institutions. In line with insights from evolutionary growth theory, and consistent with evidence on evolutionary processes triggered by the Neolithic Revolution, Wade focuses on selection during the Malthusian stage of economic development. He plausibly argues that natural selection favored growth-enhancing traits during this era when richer individuals enjoyed higher reproductive success than poorer ones, thereby increasing the representation of their traits in the population over time. ${ }^{17}$ In addition, mirroring earlier arguments from evolutionary growth theory, Wade posits that due to the egalitarian nature of hunter-gatherer societies, the forces of evolutionary selection within a society were likely to have been muted prior to the onset of the Neolithic Revolution.

In particular, generalizing based on evidence from England in the 17th century, which suggests that the rich had more surviving offspring than the poor (Clark 2007), Wade hypothesizes that in regions of the world that were historically characterized by higher population density and early statehood, favorable genetic traits (e.g., nonviolence, cooperation, and trust) that were initially concentrated among the rich elites gained an evolutionary advantage, proliferated over time, and contributed to the emergence of growth-enhancing institutions and a superior development trajectory.

Nevertheless, the traits that are central to Wade's argument (e.g., nonviolence and cooperation) need not necessarily generate higher incomes in a Malthusian environment and, thus, may not necessarily lead to

\footnotetext{
${ }^{15}$ All unattributed page references throughout the text are to Wade (2014).

${ }^{16}$ For instance, Wade argues that China's long history of civil service examinations exerted positive selection pressures on traits like "excellent memory, high intelligence and unwavering conformity" (p. 166).

${ }^{17}$ It is important to note, however, that in contrast to Wade's hypothesis, the intergenerational transmission of behavioral traits in evolutionary growth theory could be the result of cultural rather than purely genetic propagation mechanisms.
} 
higher reproductive success. In particular, in the violent society of medieval England (p. 167), where militancy and subjugation of the masses were integral to the livelihood of the aristocracy, it is likely that pacifism and trust would have hindered rather than promoted individual wealth accumulation among the elites and, thus, would not have been favored by the forces of natural selection.

The application of proper theoretical foundations could have detected whether the particular traits emphasized by Wade made individuals richer and, therefore, whether they generated higher reproductive success during the Malthusian stage of economic development. Moreover, proper theoretical foundations could also have illuminated whether the potential selection of these traits persisted once Malthusian constraints were relaxed in the transition from the epoch of stagnation in income per capita to the modern regime of sustained economic growth. Indeed, evolutionary growth theory has suggested that traits associated with higher evolutionary fitness during the Malthusian era may eventually place individuals at a disadvantage, once societies emerge into the modern growth regime (Galor and Moav 2002, 2007; Galor and Michalopoulos 2012).

\subsection{The Biological Basis of Race and Its Classification along Continental Lines}

Wade's evolutionary hypothesis underlines differential evolutionary processes across races. Citing evidence from the field of population genetics (Rosenberg et al. 2002) that genetic traits tend to be clustered at the continent level, Wade asserts that "[a]t least at the level of continental populations, races can be distinguished genetically, and this is sufficient to establish that they exist" (p. 122). In particular, Wade argues that there exists a biological underpinning to his "five-race, continent-based" classification of populations (p. 98), interpreting the evidence from population genetics as indicative of differential evolutionary processes across these groups.

Although it is conceivable that gene-culture coevolution has had a major influence on comparative development across populations and societies, it appears speculative that race in general, and Wade's classification of race in particular, is the right unit of analysis for understanding the interrelationship between human evolutionary processes and comparative development.

Importantly, the unit of analysis (i.e., race) in Wade's framework is subject to two conceptual concerns. First, the evidence from population genetics on the spatial clustering of genetic traits across major geographical regions of the world is not sufficiently well-established to support Wade's five-race, continent-based model. In particular, based on the observation that the vast majority of human genetic variation is continuously distributed across the globe, exhibiting relatively smooth "clines" or gradients generated by the "out of Africa" migration and the associated serial founder effect, several studies in population genetics have argued that classification schemes that attempt to spatially partition the worldwide human genetic variation are sensitive to methodological design, thus necessarily identifying "artificial" clusters (Kittles and Weiss 2003; Serre and Pääbo 2004). Other studies have maintained that the worldwide human genetic variation can be explained by both smooth clines within continents and clusters across continents but clarify that the portion of the overall variation explained by differences between such clusters is exceedingly small (Rosenberg et al. 2005; Li et al. 2008). Nevertheless, despite 
the fact that the genetic evidence has been contentious, Wade posits that "the five-race, continent-based scheme seems the most practical for most purposes" (p. 98).

Second, it appears that Wade's classification of populations is ultimately based on the observed variation in socioeconomic outcomes rather than on biological underpinnings per se. Wade hypothesizes that human history and comparative development are best understood in the context of five major races or "civilizations," because differences in institutions and economic development are seemingly most pronounced across major geographical regions or continents. ${ }^{18}$ Thus, in Wade's conceptual framework, the unit of analysis itself is chosen based on the ex post realization of the very outcomes (i.e., contemporary institutions and economic prosperity) that his hypothesis is attempting to explain. ${ }^{19}$

\subsection{The Causes of Institutional Variation}

Wade's evolutionary hypothesis of comparative economic development suggests that interregional variation in the selection of genetic traits forms the basis of differences in social behaviors across races, thereby shaping the variation in the nature of institutions and, thus, in long-run development outcomes across the globe.

In particular, in his attempt to establish that the worldwide variation in institutions is rooted in genetically determined differences in social behaviors across societies, Wade appeals to studies from evolutionary psychology and behavioral genetics that have associated the oxytocin hormone and the MAO-A promoter gene with cooperative and aggressive individual behavior, respectively (e.g., De Dreu et al. 2011; Beaver et al. 2013). However, an important shortcoming of these studies, particularly in the context of their broader applicability to an evolutionary hypothesis of worldwide differences in social behaviors, is that they do not establish associations between the comparative prevalence of oxytocin or the MAO-A promoter gene and the comparative prevalence of cooperative or aggressive behavior across societies. In particular, these studies focus on small localized samples of individuals and are therefore not only subject to issues of external validity but are also uninformative about the presence of the intersocietal somatic variations that are necessary for the credibility of Wade's hypothesis. For instance, the experimental study by De Dreu et al. (2011), which finds an elevated response in terms of in-group regard and out-group disregard amongst subjects "treated" with oxytocin, was only conducted on a sample of young Dutch men. Similarly, the study by Beaver et al. (2013), which finds an association between the 2-repeat allele of the MAO-A promoter gene and various indicators of aggressive or antisocial behaviors, was restricted to a sample of African-American men drawn from the National Longitudinal Study of Adolescent Health. Thus,

\footnotetext{
${ }^{18}$ For instance, Wade asserts that: "history has little coherence when analyzed in terms of individuals or even nations. But when seen in terms of the institutions developed by different civilizations and races, the outline of a logical development emerges" (p. 134).

${ }^{19}$ In particular, Wade's post hoc classification scheme, where the unit of observation is chosen to accentuate the realized variation in outcomes, gives rise to a selection bias. Namely, any potential falsification test will be a priori biased against the null hypothesis of no association between genetic traits and socioeconomic outcomes across continents, even if the cross-continental variation in the prevalence of functionally important traits is exceedingly small.
} 
these studies can only be taken as providing suggestive evidence for the possibility that variations in social behaviors across societies may be driven by their biological differences.

Further, Wade's assertion that institutional variation across societies must be rooted in differences in the prevalence of favorable genetic traits, based on the observation that a society's institutions tend to be highly persistent over time, disregards the role of cultural persistence and the well-documented role of economic incentives in shaping institutional persistence. Moreover, in contrast to Wade's hypothesis, existing findings in the economic literature tend to support the contribution of the interpersonal diversity of traits within a society to the emergence and persistence of institutions (Galor and Klemp 2017).

Incentives: In his narrative on the causes and consequences of institutional variations, Wade refers to the view of Acemoglu and Robinson (2012) that institutions are central amongst the deep determinants of comparative development. Acemoglu and Robinson have argued that a society's political elites harbor the incentive to propagate extractive institutions over time, in order to sustain and benefit from existing structures of economic and political inequality. Thus, as long as the socioeconomic environment does not alter the incentives of the elites, institutions may exhibit long-run persistence, and variations in institutions across societies and over time can only arise from "critical junctures," when an exogenous event alters this path. Although Wade acknowledges the fundamental importance of institutions for economic development, he disregards the role of economic incentives in generating institutional persistence, arguing that Acemoglu and Robinson's framework is largely unsatisfactory because it relies on the "luck" associated with historical accidents to explain differential institutional dynamics and, thus, comparative development across societies.

Wade's rejection of Acemoglu and Robinson's emphasis on historical contingencies, however, does not justify disregarding the role of economic incentives in shaping differential paths of institutional evolution across societies. Specifically, as highlighted by research in the area of unified growth theory (Galor 2011), institutional change in a society may emerge as a natural by-product of the process of development, even without appealing to the incidence of "critical junctures." In particular, Galor and Moav (2006) have argued that physical capital accumulation in the process of industrialization enhanced the importance of human capital in the production process and, thereby, generated incentives for capitalists to support the provision of public education for the masses, triggering the emergence of human capital promoting institutions. ${ }^{20}$ Further, Galor, Moav, and Vollrath (2009) have suggested that inequality in the distribution of landownership adversely affected the advent of human capital promoting institutions and, thus, the pace of the transition from an agricultural to an industrial economy. Wade's potential unfamiliarity with other plausible determinants of institutional variation across societies, leading him to consider only genetic underpinnings, undermines a crucial building block of his proposed hypothesis of comparative development.

\footnotetext{
${ }^{20}$ Ashraf et al. (2018) uncover complementary evidence suggesting the operation of similar incentives among
} capitalist elites in facilitating the decline of coercive labor institutions. 
Culture: The "dual inheritance theory" of gene-culture coevolution suggests that it is inherently challenging to disentangle the influence of genes and culture on institutions. ${ }^{21}$ As Wade himself notes, the concern regarding gene-culture separability is further complicated by the lack of scientific evidence directly linking genes to specific social behaviors: "[w]ithout knowing the nature of genes involved in social behavior, it's impossible at present to disentangle the respective roles of culture and genetics in shaping social institutions" (p. 124).

Wade nevertheless diminishes the potential for culture to impart a major influence on institutions, independently of genetic traits. In particular, Wade states that "[i]f running a productive, Western-style economy were simply a matter of culture, it should be possible for African and Middle-Eastern countries to import Western institutions and business methods, just as East Asian countries have done. But this is evidently not a straightforward task" (p. 177). Wade's dismissal of the importance of the cultural channel in institutional development is based on two assertions: first, institutional persistence is much too protracted to be explained by culture, and second, the transference of institutions across societies would have been more prevalent if they were indeed based solely on culture.

Although Wade acknowledges that cultural traits can influence a society's institutions, he maintains that given the persistence of both institutions and genetic traits, institutional differences across societies must necessarily be rooted in genetic differences. For instance, he states that "when a civilization produces a distinctive set of institutions that endures for many generations, that is the sign of a supporting suite of variations in the genes that influence human social behavior" (p. 150). This argument implicitly assumes that cultural traits cannot exhibit long-term persistence, in contrast to the views of prominent scholars in the social sciences.

For instance, Weber (1930) argued that Protestantism and its emphasis on material rewards contributed in the long run to the emergence of modern capitalism in Western societies, and Putnam (1993) suggests that idiosyncratic differences between the medieval histories of Northern vs. Southern Italy led to a sharp divergence in the degree of social capital that persists to the modern era. In addition, as emphasized by studies in evolutionary anthropology (e.g., Boyd and Richerson 1985; Henrich and Boyd 1998), cultural persistence in society could be an endogenously chosen outcome when the geographical environment is relatively stable over time, since the customs and traditions of previous generations can provide valuable information for adapting to and productively exploiting the current environment without having to engage in costly learning.

Wade further suggests that in light of existing barriers to the transfer of institutions across societies, culture cannot be a fundamental cause of institutions. He states: "[o]ne indication of such a genetic effect is that, if institutions were purely cultural, it should be easy to transfer an institution from one society to another" (p. 126). This view, however, underestimates the substantial coordination problem associated with cultural change - namely, the possibility that long-run persistence in the set of norms, values, beliefs,

\footnotetext{
${ }^{21}$ For the purposes of the present discussion, culture is viewed as the particular set of society's norms, values, beliefs, and preferences that arise from repeated social interactions amongst individuals and that can persist over time through purely "memetic" as opposed to genetic propagation, although the two transmission mechanisms are clearly highly correlated.
} 
and preferences in a given society may prevent the de facto adoption of culture and institutions from other societies in the first place. ${ }^{22}$

Thus, despite being initially transparent about the current state of knowledge regarding the inseparability of the influence of genes versus culture on socioeconomic outcomes, Wade's line of argumentation implicitly ends up assuming quite the opposite, an assumption that runs contrary to long-standing research from the fields of evolutionary anthropology and population genetics that has emphasized the notion of gene-culture coevolution (e.g., Cavalli-Sforza and Feldman 1981; Boyd and Richerson 1985; Durham 1991; Henrich and McElreath 2003).

\subsection{Comparative Development}

Wade's evolutionary hypothesis of comparative development suggests that regional variation in the forces of evolutionary selection gave rise to variation across societies in the prevalence of genetically determined behavioral traits that are conducive to growth-enhancing institutions. Since the forces of natural selection were largely muted in egalitarian hunter-gatherer societies, this selection process became fortified only after the transition to sedentary agriculture, and as such, the time elapsed since a society (or region) experienced the Neolithic Revolution governs its exposure to evolutionary processes associated with the positive selection of favorable behavioral traits. In particular, since Europe and Asia are both characterized by a long history of settled societies, Wade hypothesizes that societies in these regions have come to harbor the genetic makeup conducive to the development or adoption of growthenhancing institutions, in contrast to societies in Sub-Saharan Africa.

Instead of proposing that variation across societies in the prevalence of favorable genetic traits is a purely deterministic force in comparative development, Wade offers a more nuanced approach in which development occurs only when societies with the "proper" genetic predisposition actually implement growth-promoting institutions. In particular, Wade argues that unlike Africa, East Asia experienced economic growth and development since the mid-twentieth century because of their genetically determined ability to adopt market-friendly institutions from the West. This argument, however, is based on the existing distribution of institutions across societies rather than underlying forces that brought about such a realization. Specifically, Wade hypothesizes that African societies are unable to adopt growth-enhancing institutions based on the observation that they have not adopted them, but this form of reasoning implies that any society that has not yet adopted virtuous institutions is necessarily unable to do so. In addition, Wade's conjectures are based on the supposition that societies are generally willing to unilaterally adopt virtuous institutions (but are often unable to do so because of inappropriate genetic predispositions), disregarding the incentives of those with economic and political power in society to block institutional reform.

\footnotetext{
${ }^{22}$ In contrast to the dominant view in the social and economic sciences regarding the importance of cultural barriers to the transferability of institutions across societies, when discussing the causes of income disparities across the globe, Wade states that "in situations where culture and political institutions can flow freely across borders, long enduring disparities are harder to explain" (p. 13).
} 
Regardless of the somewhat speculative nature of Wade's hypothesis of comparative development, or the fragility of its individual building blocks, the credibility of his overarching thesis as a scientific proposition boils down to whether it is empirically falsifiable. In this respect, the fact that Wade's framework emphasizes intercontinental differences (based on his classification of race) implies that the hypothesis does not lend itself well to falsification. Setting aside the issue that his classification scheme is based on socioeconomic outcomes, the existence of only five data points (one for each continent), does not provide the necessary statistical degrees of freedom to properly account for the confounding influence of cross-continental heterogeneity in various geographical and historical forces that could have affected both the genetic-cultural makeup of societies and their economic development.

Nevertheless, Wade's narrative that economic disparities across societies may emerge from slight variations in social behaviors, due to differential selective pressures and location-specific genetic adaptations, permits a falsification test of his hypothesis based on cross-national variations (both across and within continents) in economic development and the genetic makeup of populations. Such a setup would possess the key advantage of exploiting a much larger sample size, providing the statistical degrees of freedom necessary to account for the potentially confounding influence of heterogeneity in a wide variety of geographical and historical factors, and perhaps most importantly, in other aspects of the heritable structure of human populations (namely, the degree of interpersonal diversity within populations) that were partly codetermined with the extent of genetic differentiation between populations during the prehistoric "out of Africa" diffusion of anatomically modern humans. The analysis in Section 5 below implements such a falsification test.

\section{Interpersonal Diversity, Genetic Distance to the Frontier, and Comparative Development}

This section conducts a discriminatory empirical examination of a fundamental prediction of Wade's hypothesis versus alternative evolutionary theories of comparative development. The analysis exploits contemporary variations across national populations in income per capita, interpersonal diversity, and genetic distance to the economic frontier to test whether patterns consistent with Wade's hypothesis exist in the cross-country data and whether these patterns have any bearing on the existing evidence regarding the influence of diversity on economic development, while accounting for various geographical, historical, and cultural correlates of economic development (including cultural confounders of interpersonal diversity and of genetic distance to the frontier).

Wade's evolutionary hypothesis of comparative development suggests that economically more advanced contemporary societies should be characterized by a higher prevalence of genetic traits associated with social behaviors that are conducive to economic development. To the extent that the $F_{S T}$ genetic distance between any pair of contemporary populations can serve as a reasonable metric of the difference in the prevalence of such traits, an empirically falsifiable prediction of Wade's hypothesis is that poorer contemporary societies should be characterized by a greater $F_{S T}$ genetic distance to societies that occupy the frontier of economic development in the modern world, reflecting the hypothesized lower prevalence of those favorable traits in less-developed societies. 
Although existing measures of $F_{S T}$ genetic distance for pairs of contemporary national populations are primarily based on selectively neutral genetic markers, they can be utilized to examine the effect of differences in the prevalence of functional traits on economic outcomes for two main reasons. First, since $F_{S T}$ genetic distance serves as a "molecular clock" of the time elapsed since two populations diverged from a common ancestral population, it captures the time over which interpopulation cultural and biological differences could have accumulated due to the forces of cultural and genetic drift, differential selection, and divergent gene-culture coevolution. Second, standard measures of $F_{S T}$ genetic distance for pairs of contemporary national populations (Spolaore and Wacziarg 2009) are based on underlying genetic distance data at the level of ethnic group pairs (Cavalli-Sforza, Menozzi, and Piazza 1994), incorporating information on not only selectively neutral genetic markers, thereby capturing intergroup drift due to random mutations, but also "classic" phenotypically expressed markers (e.g., ABO blood groups, Rhesus antigens, HLA, and immunoglobulins), thus further capturing potential intergroup divergence due to differential selection.

Insofar as genetically determined individual predispositions are empirically separable from the influence of culture on associated social behaviors, any credible falsification test of Wade's hypothesis would need to account for the confounding influence of cultural distance (as could be proxied by linguistic and religious distances) to the population at the economic frontier. Accounting for the influence of cultural distance is particularly important in light of the fact that the $F_{S T}$ genetic distance between any pair of populations is expected to be highly correlated with the extent of cultural divergence that arises from the forces of "cultural drift" and "isolation by distance" between the two populations (Cavalli-Sforza, Menozzi, and Piazza 1994). Moreover, because the worldwide variations in intrapopulation genetic diversity and interpopulation genetic distance were partly codetermined by the prehistoric "out of Africa" migration process, a credible empirical assessment of Wade's hypothesis cannot be made independently of the influence of interpersonal diversity on development, as documented by Ashraf and Galor (2013a). Needless to say, such an assessment also ought to account for the potentially confounding influence of various geographical characteristics and historical forces that could have shaped both the process of economic development and the composition of individual traits within societies since the completion of the "out of Africa" expansion of anatomically modern humans.

Table 1 reports the results from a cross-country analysis that simultaneously examines the influence of genetic distance to the economic frontier and the hump-shaped influence of interpersonal diversity on contemporary comparative development, while accounting for the potentially confounding effects of various geographical, historical, and cultural forces. ${ }^{23}$ The analysis considers four variations on the definition of the economic frontier, including the population of (i) the United States (columns 1-2); (ii) the United Kingdom (columns 3-4); (iii) the representative Western European or Western "offshoot" nation (columns 5-6); and (iv) the representative member nation of the OECD, including member nations from

\footnotetext{
${ }^{23}$ The data on income per capita for the 2000-2009 time period is from version 8.1 of the Penn World Table (Feenstra, Inklaar, and Timmer 2015), whereas the data on genetic, linguistic, and religious distances are sourced from Spolaore and Wacziarg (2016). The data for all other variables in the analysis in Table 1 are based on the data sets constructed by Ashraf and Galor (2013a, 2013b). The size of the cross-country sample is conditioned by the availability of data on all the variables considered by the analysis in Table 1.
} 
East Asia and Latin America (columns 7-8). For each of these variants, two separate regression models are estimated using the ordinary least squares.

The first model accounts for the potentially confounding effects of cultural distance (proxied by linguistic and religious distances) to the economic frontier; various forms of cultural diversity (including measures of fractionalization across groups differentiated by ethnic, linguistic, and religious markers in the national population); unobserved factors associated with being a previous European colony or possessing a particular legal origin (e.g., British common law vs. French civil law); and geographical characteristics (i.e., absolute latitude, agricultural suitability, terrain ruggedness, distance to the coast, temperature, precipitation, shares of land in tropical and temperate climatic zones, disease prevalence, and unobserved factors associated with being landlocked or being a small island).

The second model introduces regional dummies to account for unobserved heterogeneity across world regions. Therefore, it only exploits cross-country variations within world regions to assure that the estimated influences of interpersonal diversity and genetic distance to the economic frontier will not be confounded by cross-regional heterogeneity in unobserved geographical, cultural, and institutional factors that may have exerted an independent impact on comparative development. For instance, Diamond's (1997) hypothesis suggests that cross-continental comparative development partly reflects the role of biogeographical endowments in giving rise to the differential timing of the Neolithic Revolution across major world regions. Favorable biogeographical endowments that were associated with a larger variety of domesticable species of plants and animals, as well as continental characteristics that complemented the spatial diffusion of agricultural practices across similar climatological environments, contributed to the earlier emergence of sedentary agriculture in some regions and, thus, generated a technological head start for these regions that persisted over time. Indeed, empirical evidence from the economic literature suggests that the biogeographically driven variation in the timing of the Neolithic Revolution is instrumental for the understanding of comparative development across precolonial societies (Ashraf and Galor 2011). Thus, in the absence of regional dummies from the specification, the estimated influences of interpersonal diversity and genetic distance to the economic frontier may, for instance, capture the latent impact of unobserved biogeographical forces associated with the transition to agriculture rather than the influence of evolutionary processes per se.

In addition, although the intraregional analysis implied by the second regression model may be viewed as a deviation from the strict narrative of Wade's hypothesis, given its focus on interregional variations, it appears counterfactual that the forces of natural selection only operated differentially across continents, rather than within them as well. Indeed, much of the scientific evidence cited by Wade from human evolutionary biology points to differential genetic adaptations within world regions (e.g., prevalence of the sickle cell trait in malaria endemic areas of sub-Saharan Africa and its obscurity in other areas of the region; resistance to high-altitude sickness amongst Tibetans populations and its absence from nearby Asian populations). Therefore, barring the dilution of differences between populations as a result of genetic admixture, one would expect that the substantial heterogeneity in geographical environments within world regions generated significant variation in selective pressures and, thus, in persistent genetic adaptations across populations within continents. 


\section{[INSERT TABLE 1 HERE]}

Turning to the findings, the results reported in the odd-numbered columns of Table 1 indicate that in the absence of regional dummies from the specifications, regardless of the definition adopted for the economic frontier, the influence of genetic distance to the frontier is significantly negative, while interpersonal diversity maintains its significant hump-shaped influence on income per capita. In addition, based on the partial $R^{2}$ statistics, interpersonal diversity explains between 8.9 and 11.1 percent of the cross-country variation in the standard of living, while the explanatory power of genetic distance to the frontier for comparative development ranges between 5.3 and 9.4 percent.

However, the results reported in the even-numbered columns of Table 1 indicate that once the specifications are augmented to account for the potentially confounding effects of unobserved heterogeneity across world regions, the negative influence of genetic distance to the frontier on income per capita is no longer statistically distinguishable from zero, whereas the significant hump-shaped influence of interpersonal diversity remains qualitatively and quantitatively robust. Further, the partial $R^{2}$ statistics now reveal that interpersonal diversity explains between 13.3 and 15.9 percent of the intraregional cross-country variation in the standard of living, while the explanatory power of genetic distance to the frontier for intraregional comparative development is consistently below 1 percent. These regressions therefore demonstrate that in contrast to Ashraf and Galor's hypothesized hump-shaped influence of interpersonal diversity on aggregate productivity, Wade's evolutionary hypothesis of comparative development does not appear to hold within world regions.

In sum, to the extent that $F_{S T}$ genetic distance to the economic frontier captures a lower prevalence of favorable genetic traits in a national population, the cross-country evidence fails to support Wade's evolutionary hypothesis of comparative development. Importantly, although unobserved differences in genetic traits across major world regions could potentially still play a role in explaining broad patterns of interregional comparative development, at present these potential effects of genetic traits cannot be separately identified from the statistically correlated but nonevolutionary effects on economic development that are attributable to unobserved differences across world regions in geographical, cultural, and institutional factors.

\section{Concluding Remarks}

The past two decades have witnessed the emergence of a large and influential body of research that has focused on uncovering the evolutionary roots of comparative economic development across regions, countries, and ethnic groups. This line of inquiry has been exploring the influences of human evolution and the composition of human traits on comparative economic development across societies, highlighting the roles played by the Neolithic Revolution and the prehistoric "out of Africa" migration of anatomically modern humans in shaping variations in the composition of human traits among populations around the globe.

This exploration of the interaction between human evolution and the process of economic development has centered around two major lines of injury. The first suggests that in the era following the Neolithic Revolution, Malthusian pressures not only acted as a key determinant of the size of a population but 
conceivably shaped, via the forces of natural selection, its composition as well. Lineages of individuals whose traits were complementary to the economic environment may have generated higher levels of income and, thus, a larger number of surviving offspring. Consequently, the gradual increase in the representation of these traits in the population over time may have contributed to the process of development, the pace of the transition from stagnation to growth, and comparative economic development across societies.

The second line of research advances the hypothesis that migratory distances from the cradle of mankind in East Africa to indigenous settlements across the globe diminished their levels of interpersonal diversity and, thereby, generated a persistent hump-shaped influence on development outcomes, reflecting a fundamental trade-off between beneficial and detrimental effects of diversity on productivity at the societal level. Although diversity may reduce interpersonal trust, cooperation, and social cohesiveness, and can thus adversely affect the productivity of society, complementarity across diverse productive traits may stimulate innovations and gains from specialization, and can thereby contribute to society's economic performance.

In the context of this prominent body of research, Nicholas Wade has recently advanced a hypothesis regarding the origins of comparative development, suggesting that variation in human evolutionary processes across major continental regions since the Neolithic Revolution - particularly, in the selection of traits associated with nonviolence, cooperation, and trust - has given rise to enduring differences in social behaviors across races, thereby shaping variations in the nature of institutions and, thus, the level of economic development. As argued by this essay, however, the building blocks of Wade's hypothesis are not substantiated by the evidence. Moreover, a discriminatory empirical evaluation of existing evolutionary theories of comparative development versus Wade's hypothesis lends further credence to the hump-shaped impact of interpersonal diversity on aggregate productivity while failing to find support for Wade's evolutionary hypothesis of comparative development. 


\section{REFERENCES}

Acemoglu, Daron, and James A. Robinson. 2012. Why Nations Fail: The Origins of Power, Prosperity, and Poverty. New York: Crown Publishers.

Ager, Philipp, and Markus Brückner. Forthcoming. "Immigrants' Genes: Genetic Diversity and Economic Development in the U.S." Economic Inquiry.

Alesina, Alberto, Arnaud Devleeschauwer, William Easterly, Sergio Kurlat, and Romain Wacziarg. 2003. "Fractionalization." Journal of Economic Growth, 8(2): 155-194.

Alesina, Alberto, and Eliana La Ferrara. 2005. "Ethnic Diversity and Economic Performance." Journal of Economic Literature, 43(3): 762-800.

Arbatlı, Cemal Eren, Quamrul H. Ashraf, Oded Galor, and Marc Klemp. 2018. "Diversity and Conflict." https://ssrn.com/abstract=3138492

Ashraf, Quamrul H., Francesco Cinnirella, Oded Galor, Boris Gershman, and Erik Hornung. 2018. "Capital-Skill Complementarity and the Emergence of Labor Emancipation." Centre for Economic Policy Research Discussion Paper 12822.

Ashraf, Quamrul, and Oded Galor. 2011. "Dynamics and Stagnation in the Malthusian Epoch." American Economic Review, 101(5): 2003-2041.

Ashraf, Quamrul, and Oded Galor. 2013a. "The 'Out of Africa' Hypothesis, Human Genetic Diversity, and Comparative Economic Development." American Economic Review, 103(1): 1-46.

Ashraf, Quamrul, and Oded Galor. 2013b. "Genetic Diversity and the Origins of Cultural Fragmentation," American Economic Review, 103(3): 528-533.

Ashraf, Quamrul, Oded Galor, and Marc Klemp. 2014. "The 'Out of Africa' Hypothesis of Comparative Development Reflected by Nighttime Light Intensity." Brown University Department of Economics Working Paper 2014-4.

Ashraf, Quamrul, Oded Galor, and Marc Klemp. 2015. "Heterogeneity and Productivity." Brown University Department of Economics Working Paper 2015-4.

Ashraf, Quamrul, Oded Galor, and Marc Klemp. 2018. "Interpersonal Diversity and Societally Important Disparities across Populations: A Reply to Rosenberg and Kang." Unpublished.

Atkinson, Quentin D. 2011. "Phonemic Diversity Supports a Serial Founder Effect Model of Language Expansion from Africa." Science, 332(6027): 346-349.

Barban, Nicola, et al. 2016. "Genome-Wide Analysis Identifies 12 Loci Influencing Human Reproductive Behavior." Nature Genetics, 48(12): 1462-1472.

Beauchamp, Jonathan P., et al. 2011. "Molecular Genetics and Economics." Journal of Economic Perspectives, 25(4): 57-82.

Beaver, Kevin M., John Paul Wright, Brian B. Boutwell, J. C. Barnes, Matt DeLisi, and Michael G. Vaughn. 2013. "Exploring the Association Between the 2-Repeat Allele of the MAOA Gene Promoter Polymorphism and Psychopathic Personality Traits, Arrests, Incarceration, and Lifetime Antisocial Behavior." Personality and Individual Differences, 54(2): 164-168. 
Becker, Anke, Benjamin Enke, and Armin Falk. 2018. "Ancient Origins of the Global Variation in Economic Preferences." https://sites.google.com/site/benjaminenke/

Benjamin, Daniel J., et al. 2012. "The Genetic Architecture of Economic and Political Preferences." Proceedings of the National Academy of Sciences, 109(21): 8026-8031.

Bersaglieri, Todd, et al. 2004. "Genetic Signatures of Strong Recent Positive Selection at the Lactase Gene." American Journal of Human Genetics, 74(6): 1111-1120.

Betti, Lia, François Balloux, William Amos, Tsunehiko Hanihara, and Andrea Manica. 2009. "Distance from Africa, Not Climate, Explains Within-Population Phenotypic Diversity in Humans." Proceedings of the Royal Society B: Biological Sciences, 276(1658): 809-814.

Betti, Lia, Noreen von Cramon-Taubadel, Andrea Manica, and Stephen J. Lycett. 2013. "Global Geometric Morphometric Analyses of the Human Pelvis Reveal Substantial Neutral Population History Effects, Even across Sexes." PLOS ONE, 8(2): e55909.

Bisin, Alberto, and Thierry Verdier. 2011. "The Economics of Cultural Transmission and Socialization." In Handbook of Social Economics, Volume 1A, edited by Jess Benhabib, Alberto Bisin, and Matthew O. Jackson, 339-416. Amsterdam: North-Holland.

Bowles, Samuel, and Herbert Gintis. 2011. A Cooperative Species: Human Reciprocity and Its Evolution. Princeton: Princeton University Press.

Boyd, Robert, and Peter J. Richerson. 1985. Culture and the Evolutionary Process. Chicago: University of Chicago Press.

Burger, Joachim, Martina Kirchner, Barbara Bramanti, Wolfgang Haak, and Mark G. Thomas. 2007. "Absence of the Lactase-Persistence-Associated Allele in Early Neolithic Europeans." Proceedings of the National Academy of Sciences, 104(10): 3736-3741.

Cann, Howard M., et al. 2002. “A Human Genome Diversity Cell Line Panel.” Science, 296(5566): 261-262.

Cavalli-Sforza, L. Luca, and Marcus W. Feldman. 1981. Cultural Transmission and Evolution: A Quantitative Approach. Princeton: Princeton University Press.

Cavalli-Sforza, L. Luca, Paolo Menozzi, and Alberto Piazza. 1994. The History and Geography of Human Genes. Princeton: Princeton University Press.

Cesarini, David, Christopher T. Dawes, James H. Fowler, Magnus Johannesson, Paul Lichtenstein, and Björn Wallace. 2008. "Heritability of Cooperative Behavior in the Trust Game." Proceedings of the National Academy of Sciences, 105(10): 3721-3726.

Cesarini, David, Christopher T. Dawes, Magnus Johannesson, Paul Lichtenstein, and Björn Wallace. 2009. "Genetic Variation in Preferences for Giving and Risk Taking." Quarterly Journal of Economics, 124(2): 809-842.

Cesarini, David, Magnus Johannesson, Paul Lichtenstein, Örjan Sandewall, and Björn Wallace. 2010. "Genetic Variation in Financial Decision-Making." Journal of Finance, 65(5): 1725-1754.

Clark, Gregory. 2007. A Farewell to Alms: A Brief Economic History of the World. Princeton: Princeton University Press. 
Collins, Jason, Boris Baer, and Ernst Juerg Weber. 2014. "Economic Growth and Evolution: Parental Preference for Quality and Quantity of Offspring." Macroeconomic Dynamics, 18(8): 1773-1796.

Collins, Jason, Boris Baer, and Ernst Juerg Weber. 2015. "Sexual Selection, Conspicuous Consumption, and Economic Growth." Journal of Bioeconomics, 17(2): 189-206.

Conley, Dalton, and Jason Fletcher. 2017. The Genome Factor: What the Social Genomics Revolution Reveals about Ourselves, Our History, and the Future. Princeton: Princeton University Press.

Cook, C. Justin. 2014. "The Role of Lactase Persistence in Precolonial Development." Journal of Economic Growth, 19(4): 369-406.

Cook, C. Justin. 2015. "The Natural Selection of Infectious Disease Resistance and Its Effect on Contemporary Health." Review of Economics and Statistics, 97(4): 742-757.

Cook, C. Justin, and Jason M. Fletcher. 2017. "High School Genetic Diversity and Later-life Student Outcomes: Micro-level Evidence from the Wisconsin Longitudinal Study." National Bureau of Economic Research Working Paper 23520.

Dalgaard, Carl-Johan, and Holger Strulik. 2015. "The Physiological Foundations of the Wealth of Nations." Journal of Economic Growth, 20(1): 37-73.

Dalgaard, Carl-Johan, and Holger Strulik. 2016. "Physiology and Development: Why the West is Taller Than the Rest." Economic Journal, 126(598): 2292-2323.

De Dreu, Carsten K. W., Lindred L. Greer, Gerben A. Van Kleef, Shaul Shalvi, and Michel J. J. Handgraaf. 2011. "Oxytocin Promotes Human Ethnocentrism." Proceedings of the National Academy of Sciences, 108(4): 1262-1266.

Delis, Manthos D., Chrysovalantis Gaganis, Iftekhar Hasan, and Fotios Pasiouras. 2017. "The Effect of Board Directors from Countries with Different Genetic Diversity Levels on Corporate Performance." Management Science, 63(1): 231-249.

Depetris-Chauvin, Emilio, and Ömer Özak. 2017. "The Origins and Long-Run Consequences of the Division of Labor." Southern Methodist University Department of Economics Working Paper 1610.

Diamond, Jared. 1997. Guns, Germs, and Steel: The Fates of Human Societies. New York: W. W. Norton \& Company.

Doepke, Matthias, and Fabrizio Zilibotti. 2014. "Culture, Entrepreneurship, and Growth." In Handbook of Economic Growth, Volume 2A, edited by Philippe Aghion and Steven N. Durlauf, 1-48. Amsterdam: North-Holland.

Durham, William H. 1991. Coevolution: Genes, Culture, and Human Diversity. Stanford: Stanford University Press.

Easterly, William, and Ross Levine. 1997. "Africa's Growth Tragedy: Policies and Ethnic Divisions." Quarterly Journal of Economics, 112(4): 1203-1250.

Feenstra, Robert C., Robert Inklaar, and Marcel P. Timmer. 2015. "The Next Generation of the Penn World Table." American Economic Review, 105(10): 3150-3182.

Galor, Oded. 2011. Unified Growth Theory. Princeton: Princeton University Press. 
Galor, Oded, and Marc Klemp. 2014. "The Biocultural Origins of Human Capital Formation." National Bureau of Economic Research Working Paper 20474.

Galor, Oded, and Marc Klemp. 2017. "The Roots of Autocracy." National Bureau of Economic Research Working Paper 23301.

Galor, Oded, and Stelios Michalopoulos. 2012. "Evolution and the Growth Process: Natural Selection of Entrepreneurial Traits." Journal of Economic Theory, 147(2): 759-780.

Galor, Oded, and Omer Moav. 2002. "Natural Selection and the Origin of Economic Growth." Quarterly Journal of Economics, 117(4): 1133-1191.

Galor, Oded, and Omer Moav. 2006. "Das Human-Kapital: A Theory of the Demise of the Class Structure." Review of Economic Studies, 73(1): 85-117.

Galor, Oded, and Omer Moav. 2007. "The Neolithic Revolution and Contemporary Variations in Life Expectancy." Brown University Department of Economics Working Paper 2007-14.

Galor, Oded, and Ömer Özak. 2016. "The Agricultural Origins of Time Preference." American Economic Review, 106(10): 3064-3103.

Galor, Oded, Omer Moav, and Dietrich Vollrath. 2009. "Inequality in Landownership, the Emergence of Human-Capital Promoting Institutions, and the Great Divergence." Review of Economic Studies, 76(1): 143-179.

Hanihara, Tsunehiko. 2008. "Morphological Variation of Major Human Populations Based on Nonmetric Dental Traits." American Journal of Physical Anthropology, 136(2): 169-182.

Harpending, Henry, and Alan Rogers. 2000. "Genetic Perspectives on Human Origins and Differentiation." Annual Review of Genomics and Human Genetics, 1: 361-385.

Hawks, John, Eric T. Wang, Gregory M. Cochran, Henry C. Harpending, and Robert K. Moyzis. 2007. "Recent Acceleration of Human Adaptive Evolution." Proceedings of the National Academy of Sciences, 104(52): 20753-20758.

Henn, Brenna M., L. Luca Cavalli-Sforza, and Marcus W. Feldman. 2012. "The Great Human Expansion." Proceedings of the National Academy of Sciences, 109(44): 17758-17764.

Henrich, Joe, and Robert Boyd. 1998. "The Evolution of Conformist Transmission and the Emergence of Between-Group Differences." Evolution and Human Behavior, 19(4): 215-241.

Henrich, Joseph, and Richard McElreath. 2003. "The Evolution of Cultural Evolution." Evolutionary Anthropology, 12(3): 123-135.

Kittles, Rick A., and Kenneth M. Weiss. 2003. "Race, Ancestry, and Genes: Implications for Defining Disease Risk." Annual Review of Genomics and Human Genetics, 4: 33-67.

Kong, Augustine, et al. 2017. "Selection Against Variants in the Genome Associated with Educational Attainment." Proceedings of the National Academy of Sciences, 114(5): E727-E732.

Kong, Augustine, et al. 2018. "The Nature of Nurture: Effects of Parental Genotypes." Science, 359(6374): 424-428. 
Lagerlöf, Nils-Petter. 2007. "Long-Run Trends in Human Body Mass." Macroeconomic Dynamics, 11(3): 367-387.

Li, Jun Z., et al. 2008. "Worldwide Human Relationships Inferred from Genome-Wide Patterns of Variation." Science, 319(5866): 1100-1104.

Livingstone, Frank B. 1958. "Anthropological Implications of Sickle Cell Gene Distribution in West Africa." American Anthropologist, 60(3): 533-562.

Manica, Andrea, William Amos, François Balloux, and Tsunehiko Hanihara. 2007. "The Effect of Ancient Population Bottlenecks on Human Phenotypic Variation." Nature, 448(7151): 346-348.

Mathieson, Iain, et al. 2015. "Genome-Wide Patterns of Selection in 230 Ancient Eurasians." Nature, 528(7583): 499-503.

Mekel-Bobrov, Nitzan, et al. 2005. "Ongoing Adaptive Evolution of ASPM, a Brain Size Determinant in Homo sapiens." Science, 309(5741): 1720-1722.

Nielsen, Rasmus, Ines Hellmann, Melissa Hubisz, Carlos Bustamante, and Andrew G. Clark. 2007. "Recent and Ongoing Selection in the Human Genome." Nature Reviews Genetics, 8(11): 857-868.

Okbay, Aysu, et al. 2016. "Genome-Wide Association Study Identifies 74 Loci Associated with Educational Attainment." Nature, 533(7604): 539-542.

Pemberton, Trevor J., Michael DeGiorgio, and Noah A. Rosenberg. 2013. "Population Structure in a Comprehensive Genomic Data Set on Human Microsatellite Variation." G3: Genes, Genomes, Genetics, 3(5): 891-907.

Prugnolle, Franck, Andrea Manica, and François Balloux. 2005. "Geography Predicts Neutral Genetic Diversity of Human Populations." Current Biology, 15(5): R159-R160.

Putnam, Robert D. 1993. Making Democracy Work: Civic Traditions in Modern Italy. Princeton: Princeton University Press.

Ramachandran, Sohini, Omkar Deshpande, Charles C. Roseman, Noah A. Rosenberg, Marcus W. Feldman, and L. Luca Cavalli-Sforza. 2005. "Support from the Relationship of Genetic and Geographic Distance in Human Populations for a Serial Founder Effect Originating in Africa." Proceedings of the National Academy of Sciences, 102(44): 15942-15947.

Rietveld, Cornelius A., et al. 2013. "GWAS of 126,559 Individuals Identifies Genetic Variants Associated with Educational Attainment." Science, 340(6139): 1467-1471.

Robson, Arthur J., and Larry Samuelson. 2011. "The Evolutionary Foundations of Preferences." In Handbook of Social Economics, Volume 1A, edited by Jess Benhabib, Alberto Bisin, and Matthew 0. Jackson, 221-310. Amsterdam: North-Holland.

Rogers, Deborah S., Marcus W. Feldman, and Paul R. Ehrlich. 2009. "Inferring Population Histories using Cultural Data." Proceedings of the Royal Society B: Biological Sciences, 276(1674): 3835-3843.

Rosenberg, Noah A., and Jonathan T. L. Kang. 2015. "Genetic Diversity and Societally Important Disparities." Genetics, 201(1): 1-12. 
Rosenberg, Noah A., et al. 2002. "Genetic Structure of Human Populations." Science, 298(5602): 23812385.

Rosenberg, Noah A., Saurabh Mahajan, Sohini Ramachandran, Chengfeng Zhao, Jonathan K. Pritchard, and Marcus W. Feldman. 2005. "Clines, Clusters, and the Effect of Study Design on the Inference of Human Population Structure." PLoS Genetics, 1(6): e70.

Sabeti, Pardis C., et al. 2006. "Positive Natural Selection in the Human Lineage." Science, 312(5780): 1614-1620.

Sacerdote, Bruce. 2011. "Nature and Nurture Effects on Children's Outcomes: What Have We Learned from Studies of Twins and Adoptees?" In Handbook of Social Economics, Volume 1A, edited by Jess Benhabib, Alberto Bisin, and Matthew O. Jackson, 1-30. Amsterdam: North-Holland.

Serre, David, and Svante Pääbo. 2004. "Evidence for Gradients of Human Genetic Diversity Within and Among Continents." Genome Research, 14(9): 1679-1685.

Simonson, Tatum S., et al. 2010. "Genetic Evidence for High-Altitude Adaptation in Tibet." Science, 329(5987): 72-75.

Spolaore, Enrico, and Romain Wacziarg. 2009. "The Diffusion of Development." Quarterly Journal of Economics, 124(2): 469-529.

Spolaore, Enrico, and Romain Wacziarg. 2014. "Long-Term Barriers to Economic Development." In Handbook of Economic Growth, Volume 2A, edited by Philippe Aghion and Steven N. Durlauf, 121176. Amsterdam: North-Holland.

Spolaore, Enrico, and Romain Wacziarg. 2016. "Ancestry, Language, and Culture." In The Palgrave Handbook of Economics and Language, edited by Victor Ginsburgh and Shlomo Weber, 174-211. London: Palgrave Macmillian.

Tishkoff, Sarah A., et al. 2001. "Haplotype Diversity and Linkage Disequilibrium at Human G6PD: Recent Origin of Alleles That Confer Malarial Resistance." Science, 293(5529): 455-462.

Tishkoff, Sarah A., et al. 2007. "Convergent Adaptation of Human Lactase Persistence in Africa and Europe." Nature Genetics, 39(1): 31-40.

Voight, Benjamin F., Sridhar Kudaravalli, Xiaoquan Wen, Jonathan K. Pritchard. 2006. "A Map of Recent Positive Selection in the Human Genome." PLoS Biology, 4(3): e72.

von Cramon-Taubadel, Noreen, and Stephen J. Lycett. 2008. "Brief Communication: Human Cranial Variation Fits Iterative Founder Effect Model with African Origin." American Journal of Physical Anthropology, 136(1): 108-113.

Wade, Nicholas. 2014. A Troublesome Inheritance: Genes, Race and Human History. New York: Penguin Books.

Wallace, Björn, David Cesarini, Paul Lichtenstein, and Magnus Johannesson. 2007. "Heritability of Ultimatum Game Responder Behavior." Proceedings of the National Academy of Sciences, 104(40): 15631-15634.

Weber, Max. 1930. The Protestant Ethic and the Spirit of Capitalism. London: Allen and Unwin. 
Weibull, Jörgen W., and Marcus Salomonsson. 2006. "Natural Selection and Social Preferences." Journal of Theoretical Biology, 239(1): 79-92.

Wiesenfeld, Stephen L. 1967. "Sickle-Cell Trait in Human Biological and Cultural Evolution: Development of Agriculture Causing Increased Malaria is Bound to Gene-Pool Changes Causing Malaria Reduction." Science, 157(3793): 1134-1140. 


\section{Figures and Tables}

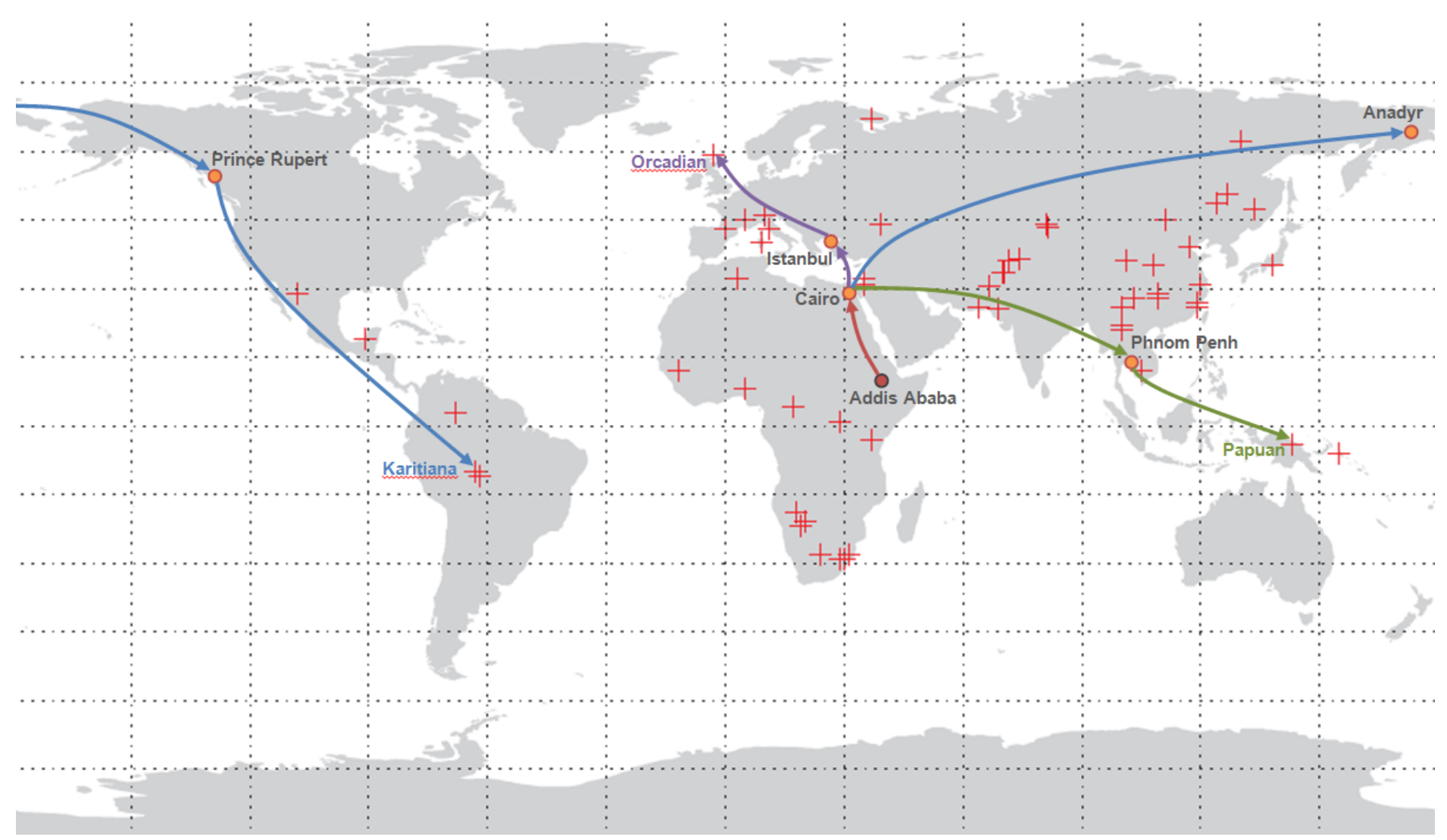

Figure 1. The "Out of Africa" Migration from the Cradle of Mankind

Notes: This figure depicts on a world map (i) the locations (denoted by crosses) of the 53 ethnic groups that constitute the HGDP-CEPH Human Genome Diversity Cell Line Panel; (ii) the locations (denoted by circles) of the intermediate waypoints used to construct the land-connected migratory paths from Addis Ababa to these ethnic groups; and (iii) some migratory paths (denoted by solid lines) based on these waypoints.

Source: Ashraf and Galor (2013a). 


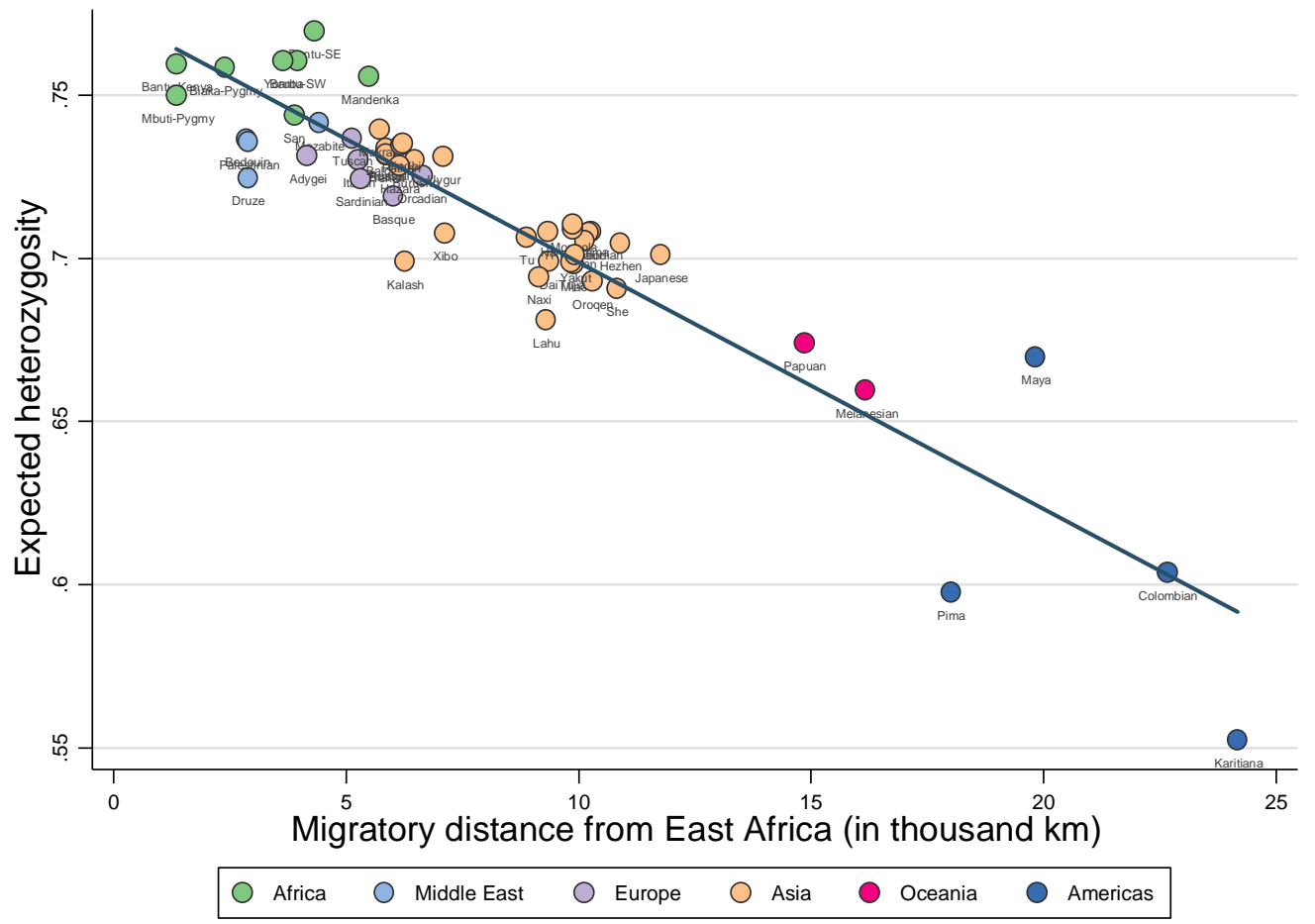

Figure 2. Expected Heterozygosity and Migratory Distance from East Africa

Notes: This figure depicts the negative influence of migratory distance from East Africa on expected heterozygosity (genetic diversity) across the 53 ethnic groups that constitute the HGDP-CEPH Human Genome Diversity Cell Line Panel.

Source: Ashraf and Galor (2013a). 


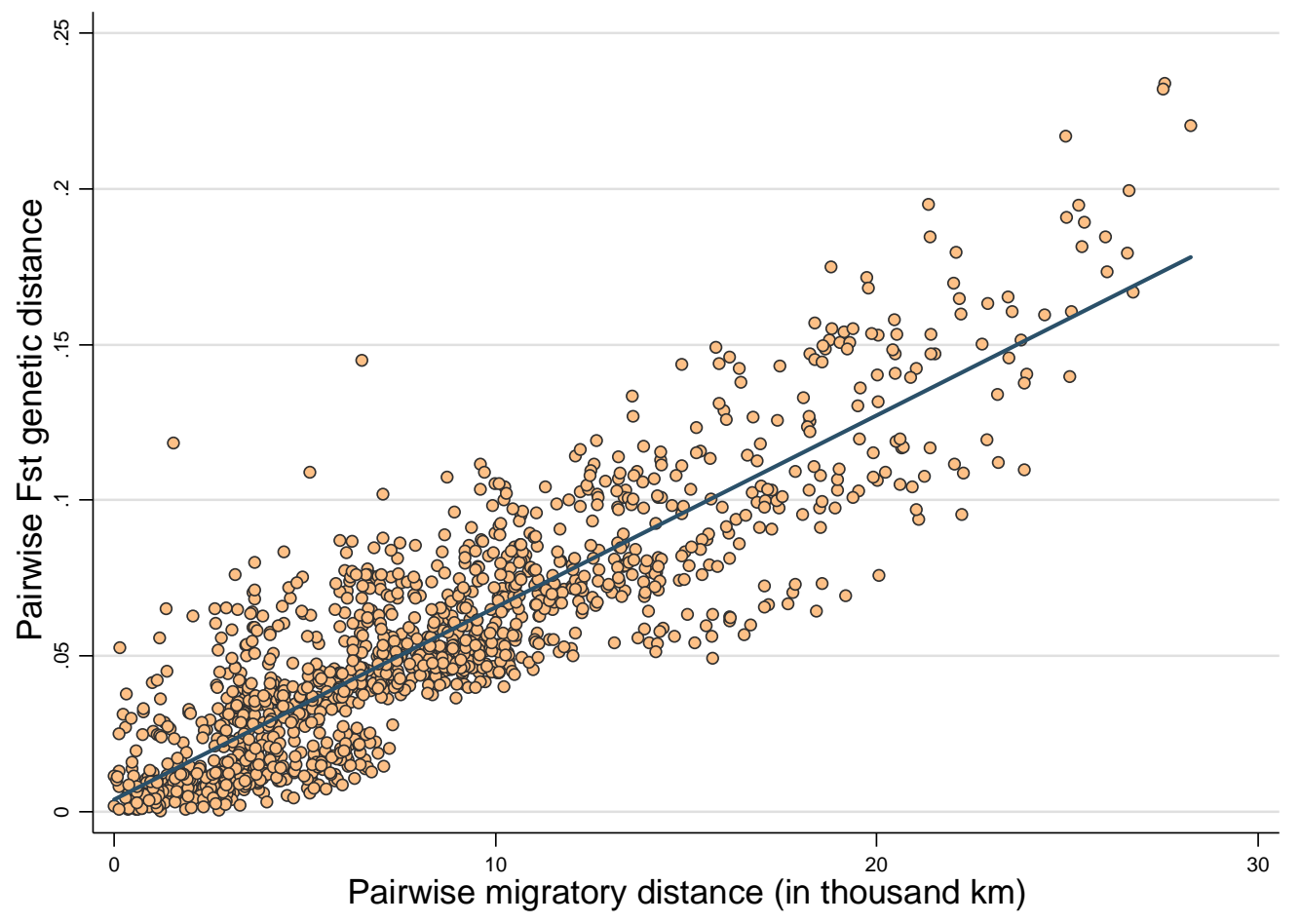

Figure 3. Pairwise $F_{S T}$ Genetic Distance and Pairwise Migratory Distance

Notes: This figure depicts the positive influence of pairwise migratory distance on pairwise $F_{S T}$ genetic distance across all 1,378 ethnic group pairs from the set of 53 ethnic groups that constitute the HGDP-CEPH Human Genome Diversity Cell Line Panel.

Source: Ashraf and Galor (2013a). 
Panel A:

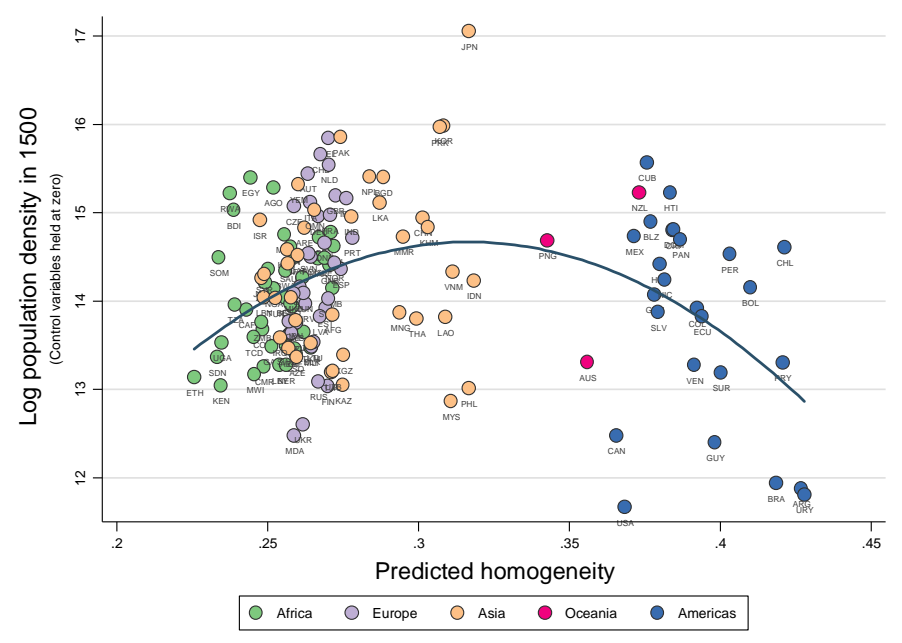

Panel B:

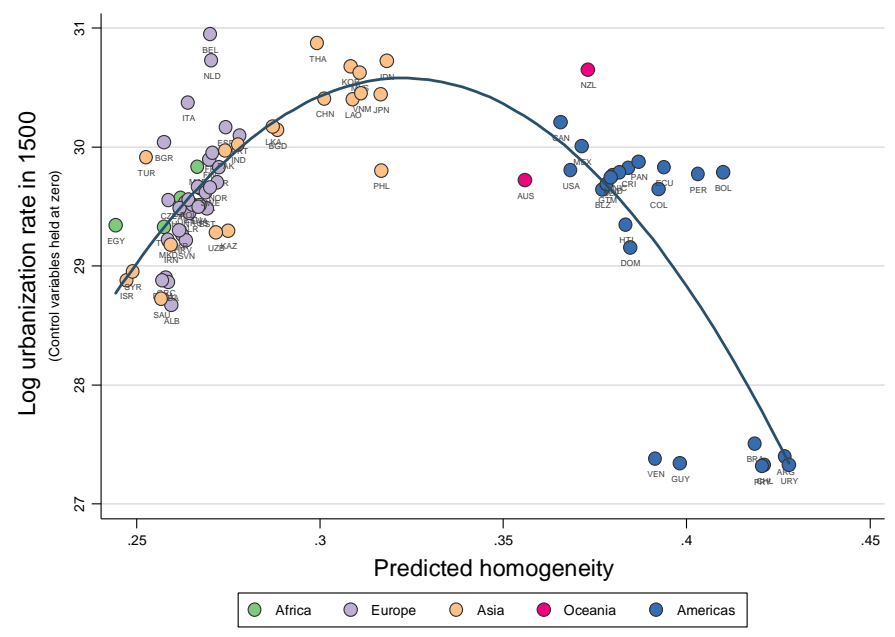

Figure 4. Interpersonal Diversity and Historical Comparative Development across Countries

Notes: This figure depicts the cross-country hump-shaped influence of predicted homogeneity (i.e., 1 minus interpersonal diversity predicted by migratory distance from East Africa) on economic development in the year 1500, as reflected by either log population density (Panel A) or log urbanization rate (Panel B), conditional on the timing of the Neolithic Revolution, land productivity, and continent/regional fixed effects. Please refer to Ashraf and Galor (2013a) for additional details.

Source: Ashraf and Galor (2013a). 
Panel A:

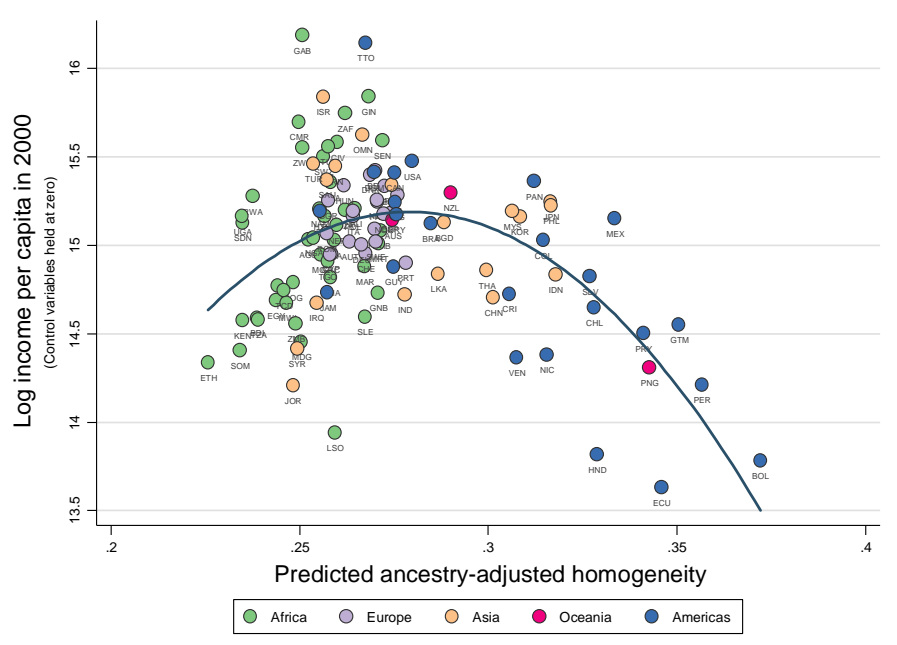

Panel B:

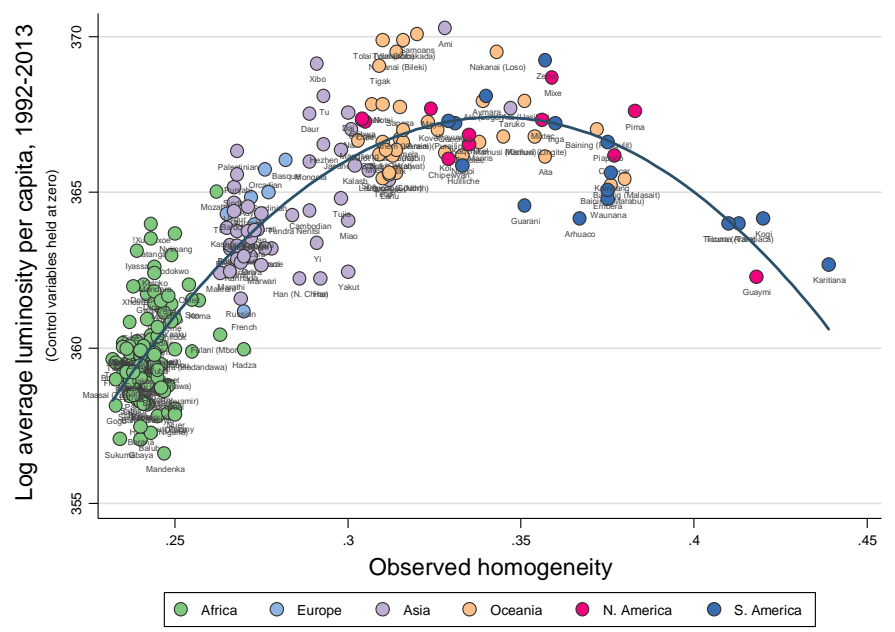

Figure 5. Interpersonal Diversity and Contemporary Comparative Development across Countries and Ethnic Groups

Notes: This figure depicts the hump-shaped influence of interpersonal diversity on contemporary economic development across countries and ethnic groups. Panel A depicts the relationship across countries between predicted ancestry-adjusted homogeneity (i.e., 1 minus interpersonal diversity predicted by the migratory distances of a country's ancestral populations from East Africa and the pairwise migratory distances among them) and log income per capita in the year 2000, conditional on the ancestry-adjusted timing of the Neolithic Revolution, land productivity, a vector of institutional, cultural, and geographical determinants of development, and continent/regional fixed effects. Panel B depicts the relationship across ethnic groups between observed homogeneity (i.e., 1 minus expected heterozygosity) and log average light intensity per capita in the 1992-2013 time horizon, conditional on absolute latitude, soil quality, type of landmass, group size, institutional characteristics (extent of jurisdictional hierarchy and type of class stratification), and regional fixed effects. Please refer to Ashraf and Galor (2013a) and Ashraf, Galor, and Klemp (2015) for additional details.

Sources: Ashraf and Galor (2013a) and Ashraf, Galor, and Klemp (2015). 


\section{Panel A:}

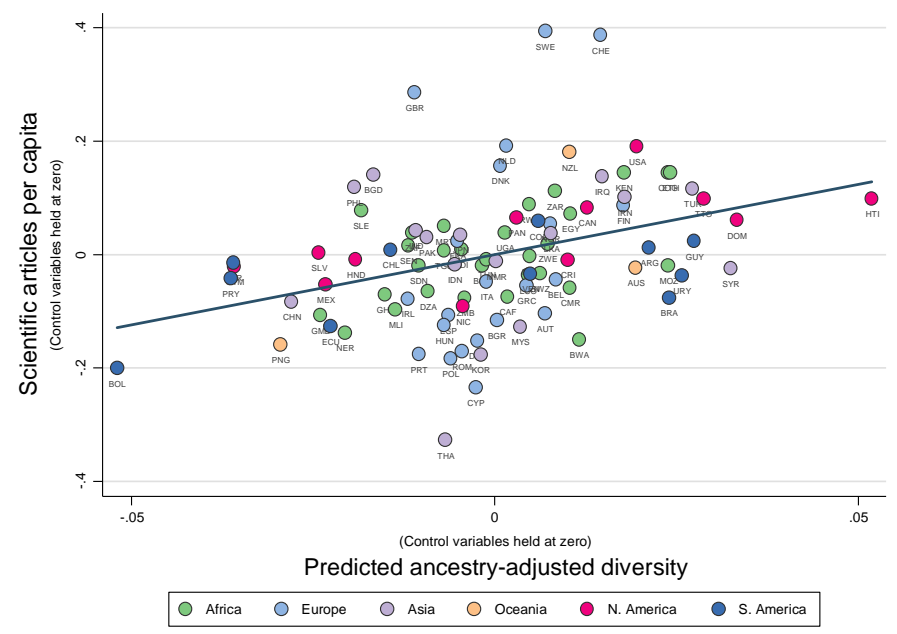

Panel C:

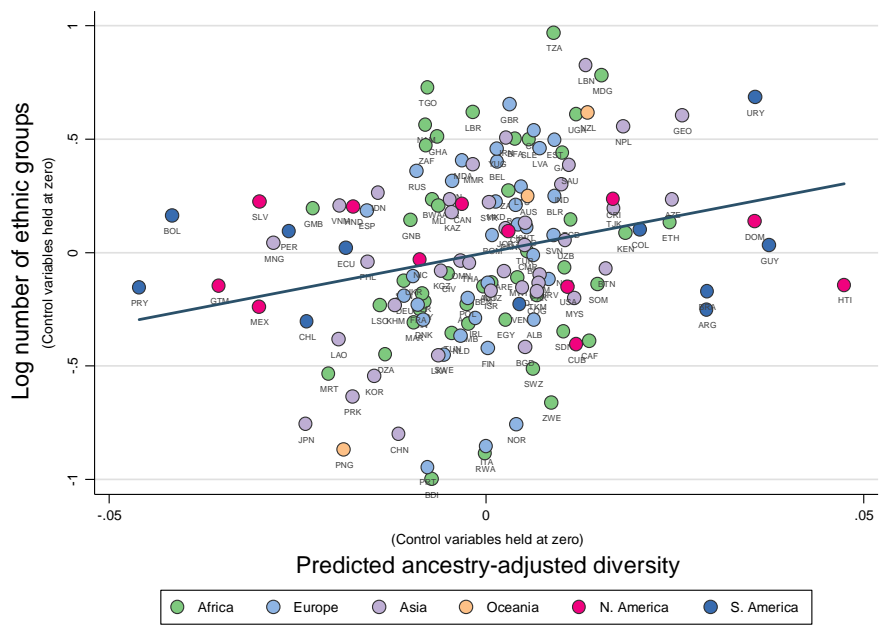

Panel E:

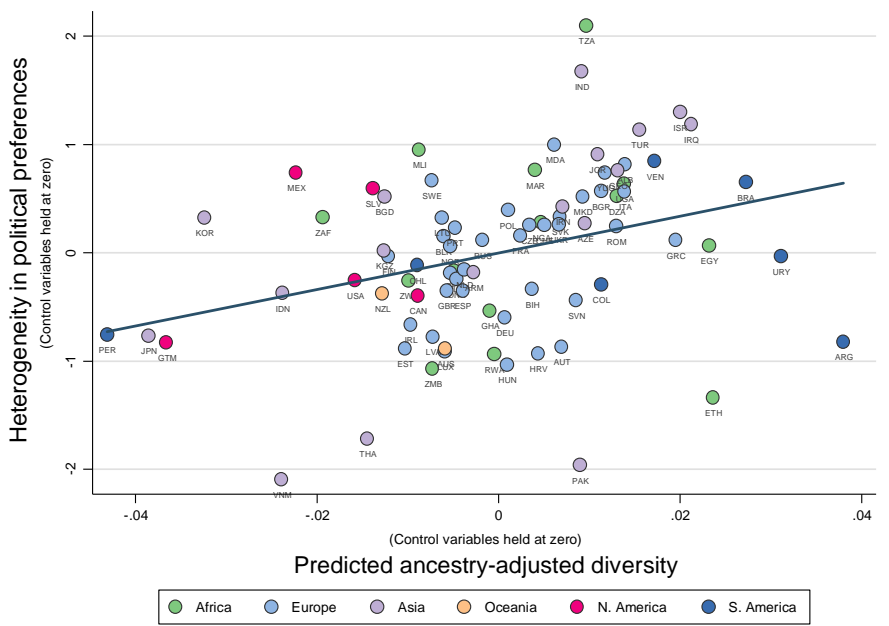

Panel B:

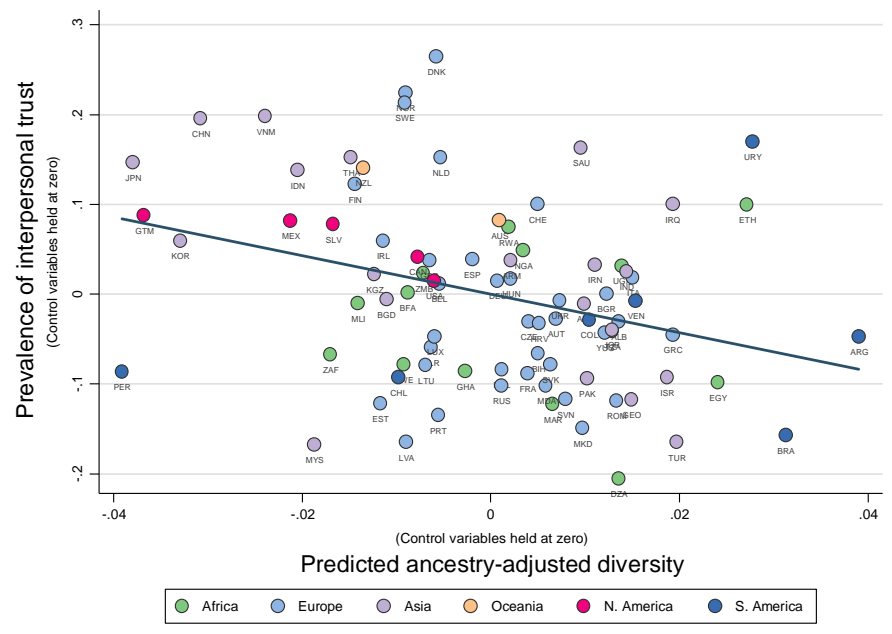

Panel D:

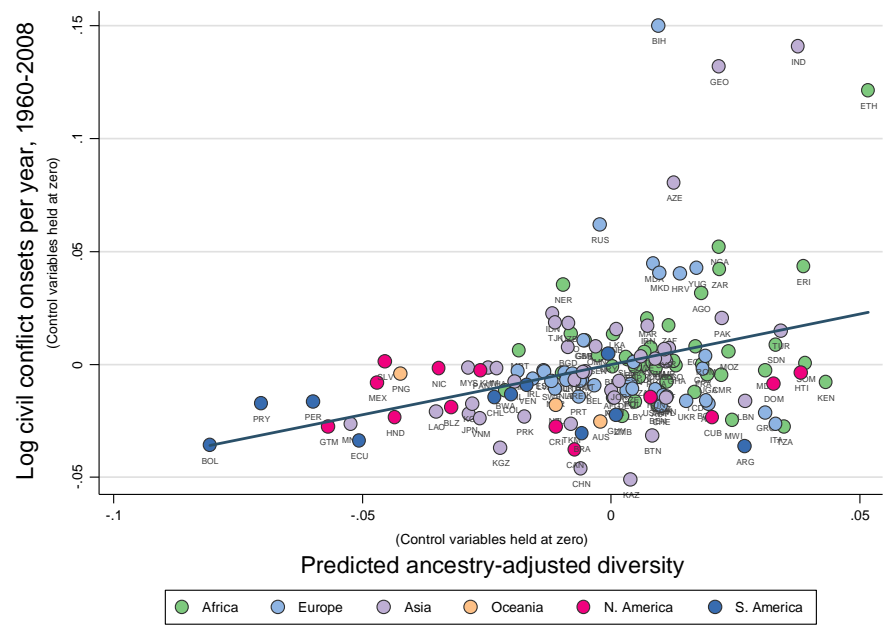

Figure 6. Mechanisms of the Impact of Interpersonal Diversity on Aggregate Productivity 
Notes: This figure depicts the cross-country associations between predicted ancestry-adjusted diversity and (i) the average annual number of scientific articles per capita in the 1981-2000 time horizon (Panel A); (ii) the prevalence of interpersonal trust in data from the World Values Survey, 1981-2008 (Panel B); (iii) the number of ethnic groups (Panel C); (iv) the annual frequency of new civil conflict onsets in the 1960-2008 time horizon (Panel D); and (v) the intracountry dispersion in individual political attitudes (expressed on a politically "left"-_right" categorical scale) in data from the World Values Survey (Panel E). Each relationship is conditioned on a sizeable vector of control variables relevant for explaining the outcome of interest. Please refer to Ashraf and Galor (2013a, 2013b) and Arbatlı et al. (2018) for additional details.

Sources: Ashraf and Galor (2013a, 2013b) and Arbatlı et al. (2018). 
TABLE 1

Interpersonal Diversity, Genetic Distance to the Frontier, and Comparative Development

\begin{tabular}{|c|c|c|c|c|c|c|c|c|}
\hline & (1) & $(2)$ & (3) & (4) & $(5)$ & (6) & (7) & (8) \\
\hline & \multicolumn{8}{|c|}{ Dependent variable is log of average real GDP per capita, 2000-2009 } \\
\hline & \multicolumn{2}{|c|}{ Frontier $=$ U.S. } & \multicolumn{2}{|c|}{ Frontier $=$ U.K. } & \multicolumn{2}{|c|}{ Frontier $=$ Western } & \multicolumn{2}{|c|}{ Frontier $=\mathrm{OECD}$} \\
\hline Predicted diversity & $\begin{array}{c}239.402^{* * *} \\
(80.920)\end{array}$ & $\begin{array}{c}299.374 * * * \\
(82.710)\end{array}$ & $\begin{array}{c}278.323^{* * *} \\
(86.736)\end{array}$ & $\begin{array}{c}296.325 * * * \\
(82.002)\end{array}$ & $\begin{array}{c}268.883^{* * *} \\
(88.444)\end{array}$ & $\begin{array}{c}307.484^{* * *} \\
(84.966)\end{array}$ & $\begin{array}{c}255.392^{* * *} \\
(93.376)\end{array}$ & $\begin{array}{c}285.992^{* * *} \\
(88.979)\end{array}$ \\
\hline Predicted diversity squared & $\begin{array}{c}-177.836^{* * *} \\
(58.334)\end{array}$ & $\begin{array}{c}-213.209 * * * \\
(59.678)\end{array}$ & $\begin{array}{c}-205.565^{* * *} \\
(62.390)\end{array}$ & $\begin{array}{c}-211.081^{* * *} \\
(59.100)\end{array}$ & $\begin{array}{c}-198.069 * * * \\
(63.640)\end{array}$ & $\begin{array}{c}-219.301 * * * \\
(61.257)\end{array}$ & $\begin{array}{c}-187.765 * * * \\
(67.164)\end{array}$ & $\begin{array}{c}-204.178^{* * *} \\
(64.041)\end{array}$ \\
\hline Genetic distance to the frontier & $\begin{array}{c}-5.262^{* * *} \\
(1.944)\end{array}$ & $\begin{array}{c}1.368 \\
(2.177)\end{array}$ & $\begin{array}{c}-4.937^{* * *} \\
(1.535)\end{array}$ & $\begin{array}{c}0.919 \\
(1.798)\end{array}$ & $\begin{array}{c}-4.386^{* *} \\
(1.948)\end{array}$ & $\begin{array}{c}1.621 \\
(2.200)\end{array}$ & $\begin{array}{c}-4.513^{* *} \\
(2.098)\end{array}$ & $\begin{array}{c}2.410 \\
(2.343)\end{array}$ \\
\hline Linguistic distance to the frontier & $\begin{array}{c}0.555 \\
(0.701)\end{array}$ & $\begin{array}{c}0.869 \\
(0.636)\end{array}$ & $\begin{array}{c}1.166 \\
(0.925)\end{array}$ & $\begin{array}{l}1.372 * \\
(0.722)\end{array}$ & $\begin{array}{l}-0.838 \\
(2.033)\end{array}$ & $\begin{array}{c}0.344 \\
(1.800)\end{array}$ & $\begin{array}{r}-1.660 \\
(2.619)\end{array}$ & $\begin{array}{l}-1.475 \\
(2.160)\end{array}$ \\
\hline Religious distance to the frontier & $\begin{array}{c}-2.102^{* * *} \\
(0.603)\end{array}$ & $\begin{array}{c}-1.391^{*} \\
(0.720)\end{array}$ & $\begin{array}{c}-1.890 * * \\
(0.750)\end{array}$ & $\begin{array}{l}-1.406 \\
(0.937)\end{array}$ & $\begin{array}{c}-2.024^{* * *} \\
(0.657)\end{array}$ & $\begin{array}{c}-1.712^{* *} \\
(0.845)\end{array}$ & $\begin{array}{c}-2.070^{* * *} \\
(0.724)\end{array}$ & $\begin{array}{l}-1.720 * \\
(0.876)\end{array}$ \\
\hline Ethnic fractionalization & $\begin{array}{l}-0.547 \\
(0.451)\end{array}$ & $\begin{array}{l}-0.192 \\
(0.392)\end{array}$ & $\begin{array}{l}-0.431 \\
(0.457)\end{array}$ & $\begin{array}{l}-0.244 \\
(0.399)\end{array}$ & $\begin{array}{l}-0.500 \\
(0.414)\end{array}$ & $\begin{array}{l}-0.187 \\
(0.379)\end{array}$ & $\begin{array}{l}-0.542 \\
(0.413)\end{array}$ & $\begin{array}{l}-0.201 \\
(0.373)\end{array}$ \\
\hline Linguistic fractionalization & $\begin{array}{l}-0.372 \\
(0.390)\end{array}$ & $\begin{array}{l}-0.106 \\
(0.320)\end{array}$ & $\begin{array}{l}-0.442 \\
(0.409)\end{array}$ & $\begin{array}{l}-0.098 \\
(0.326)\end{array}$ & $\begin{array}{l}-0.328 \\
(0.365)\end{array}$ & $\begin{array}{l}-0.090 \\
(0.303)\end{array}$ & $\begin{array}{l}-0.261 \\
(0.366)\end{array}$ & $\begin{array}{l}-0.044 \\
(0.296)\end{array}$ \\
\hline Religious fractionalization & $\begin{array}{c}1.077^{* * *} \\
(0.400)\end{array}$ & $\begin{array}{c}1.013^{* * *} \\
(0.322)\end{array}$ & $\begin{array}{c}1.204^{* * *} \\
(0.403)\end{array}$ & $\begin{array}{c}1.068^{* * *} \\
(0.323)\end{array}$ & $\begin{array}{c}1.072 * * * \\
(0.404)\end{array}$ & $\begin{array}{c}0.964^{* * *} \\
(0.320)\end{array}$ & $\begin{array}{c}1.059 * * * \\
(0.402)\end{array}$ & $\begin{array}{c}0.912^{* * *} \\
(0.315)\end{array}$ \\
\hline Absolute latitude & $\begin{array}{l}-0.003 \\
(0.017)\end{array}$ & $\begin{array}{l}-0.007 \\
(0.014)\end{array}$ & $\begin{array}{l}-0.010 \\
(0.017)\end{array}$ & $\begin{array}{l}-0.008 \\
(0.014)\end{array}$ & $\begin{array}{l}-0.006 \\
(0.016)\end{array}$ & $\begin{array}{l}-0.007 \\
(0.014)\end{array}$ & $\begin{array}{l}-0.004 \\
(0.017)\end{array}$ & $\begin{array}{l}-0.004 \\
(0.015)\end{array}$ \\
\hline Agricultural suitability & $\begin{array}{c}-1.035^{* * *} \\
(0.392)\end{array}$ & $\begin{array}{c}-0.878^{* *} \\
(0.363)\end{array}$ & $\begin{array}{c}-0.960 * * \\
(0.398)\end{array}$ & $\begin{array}{c}-0.933^{* *} \\
(0.372)\end{array}$ & $\begin{array}{c}-0.988 * * \\
(0.382)\end{array}$ & $\begin{array}{c}-0.819 * * \\
(0.363)\end{array}$ & $\begin{array}{c}-1.036^{* * *} \\
(0.371)\end{array}$ & $\begin{array}{c}-0.794^{* *} \\
(0.353)\end{array}$ \\
\hline Terrain ruggedness & $\begin{array}{c}-0.001^{*} \\
(0.001)\end{array}$ & $\begin{array}{c}-0.001^{*} \\
(0.001)\end{array}$ & $\begin{array}{c}-0.001^{* *} \\
(0.001)\end{array}$ & $\begin{array}{c}-0.001^{*} \\
(0.001)\end{array}$ & $\begin{array}{c}-0.001^{*} \\
(0.001)\end{array}$ & $\begin{array}{c}-0.001 * \\
(0.001)\end{array}$ & $\begin{array}{l}-0.001 \\
(0.001)\end{array}$ & $\begin{array}{c}-0.001 * \\
(0.001)\end{array}$ \\
\hline Distance to coast & $\begin{array}{c}-0.394^{*} \\
(0.229)\end{array}$ & $\begin{array}{l}-0.383 \\
(0.231)\end{array}$ & $\begin{array}{c}-0.487^{* *} \\
(0.223)\end{array}$ & $\begin{array}{c}-0.412 * \\
(0.224)\end{array}$ & $\begin{array}{c}-0.459 * * \\
(0.228)\end{array}$ & $\begin{array}{c}-0.386^{*} \\
(0.231)\end{array}$ & $\begin{array}{l}-0.435^{*} \\
(0.228)\end{array}$ & $\begin{array}{l}-0.365 \\
(0.232)\end{array}$ \\
\hline Mean monthly temperature & $\begin{array}{l}-0.897 \\
(2.594)\end{array}$ & $\begin{array}{c}0.725 \\
(2.153)\end{array}$ & $\begin{array}{l}-2.754 \\
(2.676)\end{array}$ & $\begin{array}{c}0.716 \\
(2.166)\end{array}$ & $\begin{array}{l}-0.976 \\
(2.448)\end{array}$ & $\begin{array}{c}0.938 \\
(2.166)\end{array}$ & $\begin{array}{l}-0.597 \\
(2.489)\end{array}$ & $\begin{array}{c}1.313 \\
(2.219)\end{array}$ \\
\hline Mean monthly precipitation & $\begin{array}{l}-0.212 \\
(0.269)\end{array}$ & $\begin{array}{l}-0.242 \\
(0.209)\end{array}$ & $\begin{array}{l}-0.281 \\
(0.274)\end{array}$ & $\begin{array}{l}-0.263 \\
(0.207)\end{array}$ & $\begin{array}{l}-0.264 \\
(0.263)\end{array}$ & $\begin{array}{l}-0.226 \\
(0.210)\end{array}$ & $\begin{array}{l}-0.253 \\
(0.262)\end{array}$ & $\begin{array}{l}-0.197 \\
(0.210)\end{array}$ \\
\hline$\%$ land area in tropical and subtropical zones & $\begin{array}{l}-0.410 \\
(0.328)\end{array}$ & $\begin{array}{l}-0.497^{*} \\
(0.253)\end{array}$ & $\begin{array}{l}-0.437 \\
(0.321)\end{array}$ & $\begin{array}{l}-0.488^{*} \\
(0.254)\end{array}$ & $\begin{array}{l}-0.429 \\
(0.321)\end{array}$ & $\begin{array}{c}-0.512 * * \\
(0.253)\end{array}$ & $\begin{array}{l}-0.424 \\
(0.326)\end{array}$ & $\begin{array}{c}-0.525 * * \\
(0.255)\end{array}$ \\
\hline$\%$ land area in temperate zones & $\begin{array}{c}0.293 \\
(0.320)\end{array}$ & $\begin{array}{c}0.423 \\
(0.271)\end{array}$ & $\begin{array}{c}0.353 \\
(0.320)\end{array}$ & $\begin{array}{c}0.438 \\
(0.278)\end{array}$ & $\begin{array}{c}0.294 \\
(0.316)\end{array}$ & $\begin{array}{c}0.413 \\
(0.269)\end{array}$ & $\begin{array}{c}0.296 \\
(0.313)\end{array}$ & $\begin{array}{c}0.378 \\
(0.264)\end{array}$ \\
\hline Disease richness & $\begin{array}{l}-0.003 \\
(0.006)\end{array}$ & $\begin{array}{l}-0.003 \\
(0.006)\end{array}$ & $\begin{array}{c}0.000 \\
(0.007)\end{array}$ & $\begin{array}{l}-0.003 \\
(0.006)\end{array}$ & $\begin{array}{c}0.001 \\
(0.006)\end{array}$ & $\begin{array}{l}-0.001 \\
(0.006)\end{array}$ & $\begin{array}{c}0.000 \\
(0.006)\end{array}$ & $\begin{array}{l}-0.000 \\
(0.006)\end{array}$ \\
\hline Landlocked and small island fixed effects & Yes & Yes & Yes & Yes & Yes & Yes & Yes & Yes \\
\hline Colonial history and legal origin fixed effects & Yes & Yes & Yes & Yes & Yes & Yes & Yes & Yes \\
\hline Regional fixed effects & No & Yes & No & Yes & No & Yes & No & Yes \\
\hline Observations & 127 & 127 & 127 & 127 & 127 & 127 & 127 & 127 \\
\hline Partial R2 of predicted diversity & 0.091 & 0.159 & 0.111 & 0.152 & 0.104 & 0.157 & 0.089 & 0.133 \\
\hline Partial R2 of genetic distance & 0.068 & 0.003 & 0.094 & 0.002 & 0.057 & 0.005 & 0.053 & 0.009 \\
\hline Partial R2 sum of all distance measures & 0.162 & 0.049 & 0.170 & 0.051 & 0.130 & 0.051 & 0.121 & 0.056 \\
\hline Adjusted R2 & 0.751 & 0.809 & 0.740 & 0.807 & 0.758 & 0.810 & 0.761 & 0.813 \\
\hline
\end{tabular}

Notes: The analysis in this table exploits cross-country variations to examine the influences of predicted ancestry-adjusted interpersonal diversity (based on the migratory distances of a country's ancestral populations from East Africa and the pairwise migratory distances among them) and genetic distance to the economic frontier on economic development, conditional on the potentially confounding effects of cultural distance (as proxied by linguistic and religious distances) to the frontier; measures of ethnic, linguistic, and religious fractionalization; various geographical, topographical, and climatological characteristics; and institutional 
factors associated with historical colonial experience. The specifications presented in even-numbered columns additionally control for regional fixed effects. The various measures of genetic, linguistic, and religious distances considered by the analysis include (a) distances to the contemporary population of the U.S. [columns 1-2]; (b) distances to the contemporary population of the U.K. [columns 3-4]; (c) mean distances to the contemporary populations of Western European and Western offshoot nations [columns 56]; and (d) mean distances to the contemporary populations of the OECD member nations, including nations from Asia and Latin America [columns 7-8]. The set of legal origin fixed effects include dummies for British, French, Socialist, and Scandinavian legal origins. The set of regional fixed effects include dummies for the Sub-Saharan Africa, Middle East and North Africa, Europe and Central Asia, South Asia, East Asia and Pacific, North America, and Latin America and Caribbean regions. Heteroskedasticity robust standard errors are reported in parentheses. ${ }^{* * *}$ denotes statistical significant at the 1 percent level, ${ }^{* *}$ at the 5 percent level, and ${ }^{*}$ at the 10 percent level. 